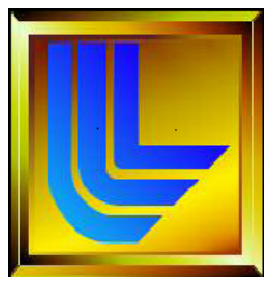

UCRL-JRNL-201012

\title{
Characterizing Unsaturated Diffusion in Porous Tuff Gravel
} \author{
Wang $^{2}$ \\ ${ }^{1} 7000$ East Avenue, MS L-231 \\ Lawrence Livermore National Laboratory \\ Livermore, CA 94550 \\ 21 Cyclotron Road, MS 90-1116 \\ Lawrence Berkeley National Laboratory \\ Berkeley, CA 94720
}

Qinhong $\mathrm{Hu}^{1, *}$, Timothy J. Kneafsey ${ }^{2}$, Jeffery J. Roberts ${ }^{1}$, Liviu Tomutsa ${ }^{2}$, and Joseph S.Y.

Prepared For:

Vadose Zone Journal

November 12, 2003

*Corresponding author (phone: 925-422-6774; fax: 925-422-3160; email: hu7@1lnl.gov)

Approved for public release; further dissemination unlimited 


\section{DISCLAIMER}

This document was prepared as an account of work sponsored by an agency of the United States Government. Neither the United States Government nor the University of California nor any of their employees, makes any warranty, express or implied, or assumes any legal liability or responsibility for the accuracy, completeness, or usefulness of any information, apparatus, product, or process disclosed, or represents that its use would not infringe privately owned rights. Reference herein to any specific commercial product, process, or service by trade name, trademark, manufacturer, or otherwise, does not necessarily constitute or imply its endorsement, recommendation, or favoring by the United States Government or the University of California. The views and opinions of authors expressed herein do not necessarily state or reflect those of the United States Government or the University of California, and shall not be used for advertising or product endorsement purposes.

This work was performed under the auspices of the U. S. Department of Energy by the University of California, Lawrence Livermore National Laboratory under Contract No. W-7405-Eng-48.

This report has been reproduced directly from the best available copy.

Available to DOE and DOE contractors from the

Office of Scientific and Technical Information

P.O. Box 62, Oak Ridge, TN 37831

Prices available from (423) 576-8401

http://apollo.osti.gov/bridge/

Available to the public from the

National Technical Information Service

U.S. Department of Commerce

5285 Port Royal Rd., Springfield, VA 22161

http://www.ntis.gov/

OR

Lawrence Livermore National Laboratory

Technical Information Department's Digital Library

http://www.llnl.gov/tid/Library.html 
UCRL-JRNL-201012

\begin{abstract}
Evaluation of solute diffusion in unsaturated porous gravel is very important for investigations of contaminant transport and remediation, risk assessment, and waste disposal (e.g., the potential high-level nuclear waste repository at Yucca Mountain, Nevada). For a porous aggregate medium such as granular tuff, the total water content is comprised of surface water and interior water. The surface water component (water film around grains and pendular water between the grain contacts) could serve as a predominant diffusion pathway. To investigate the extent of surface water films and contact points affect solute diffusion in unsaturated gravel, we examined the configuration of water using x-ray computed tomography in partially saturated gravel, and made quantitative measurements of diffusion at multiple water contents using two different techniques. In the first, diffusion coefficients of potassium chloride in 2-4 mm granular tuff at multiple water contents are calculated from electrical conductivity measurements using the Nernst-Einstein equation. In the second, we used laser ablation with inductively coupled plasmamass spectrometry to perform micro-scale mapping, allowing the measurement of diffusion coefficients for a mixture of chemical tracers for tuff cubes and tetrahedrons having two contact geometries (cube-cube and cube-tetrahedron). The x-ray computed tomography images show limited contact between grains, and this could significantly hinder the pathways for diffusive transport. Experimental results show the critical role of surface water in controlling transport pathways and hence the magnitude of diffusion. Even with a bulk volumetric water content of $1.5 \%$, the measured solute diffusion coefficient is as low as $1.5 \times 10^{-14} \mathrm{~m}^{2} / \mathrm{s}$. Currently used diffusion models relating diffusion coefficients to total volumetric water content inadequately describe unsaturated diffusion behavior in porous gravel.
\end{abstract}


UCRL-JRNL-201012

\section{INTRODUCTION}

Studies of flow and transport in gravels have recently received attention because of the importance of gravel aquifers, the need to understand contamination characterization and remediation of gravel deposits in the vadose zone, and its usage as capillary barriers for waste isolation. As stated in Tokunaga et al. (2003), relatively little information is available on the unsaturated hydraulic properties of gravels; this is also true for transport processes in unsaturated gravel systems. Conca and coworkers published pioneering work examining chemical diffusion behavior in porous gravels, yet this work was conducted more than ten years ago (Conca, 1990; Conca and Wright, 1990; Conca and Wright, 1992). With the improved understanding of water distribution in gravel, there is a strong need to investigate the diffusion processes in unsaturated porous gravel by employing the latest developments in instrumentation and techniques. Improved understanding of unsaturated diffusion in gravel will help in the characterization and remediation effort in gravel deposits at the Hanford Site in Washington State. It will also help in the invert diffusion barrier concept in the potential underground high-level radioactive waste repository at Yucca Mountain, Nevada, where tuff gravel has been considered as an invert material (material filling the bottom of a tunnel having a circular cross section) to contain radionuclide transport.

The invert placed between the waste package/drip shield and the tuff host rock at Yucca Mountain is an integral component of repository performance. If effective, an invert diffusion barrier (caused by slow radionuclide diffusion through the invert) can greatly enhance wasteisolation capacity. The diffusion data set reported by Conca and Wright (1992) is generally well correlated in terms of a power-dependence on the volumetric water content. This "universal" power function has been used to represent diffusive transport of radionuclides through the invert (CRWMS M\&O, 2000b), without taking into consideration any unique properties of invert materials. In the waste emplacement drifts, characterized by a humid environment with or without 
1 the presence of liquid water, crushed porous rock may provide unique characteristics that vary

2 greatly from this generic power function (Wang et al., 2001; Hu and Wang, 2003). For example,

3 Conca (1990) has inferred the existence of a very low diffusion coefficient in tuff gravel samples

4 placed in a $100 \%$ relative humidity $(\mathrm{RH})$ environment. At equilibrium, all samples of single grains

5 were observed to be dry, despite the $2.7 \%$ water content. No electrical conductivity could be

6 measured, resulting in an inferred diffusion coefficient below $10^{-15} \mathrm{~m}^{2} / \mathrm{s}$. This value is the

7 detection limit reported by Conca (1990) using electrical conductivity (EC) for estimating the

8 diffusion coefficient. The inferred low diffusion value of $10^{-15} \mathrm{~m}^{2} / \mathrm{s}$ at this water content deviates

9 significantly from the "universal" power function with a diffusion coefficient (about $2.8 \times 10^{-12}$

$10 \mathrm{~m}^{2} / \mathrm{s}$ ), which is obtained with continuous fluid introduction. In other words, at the same total

11 water content, diffusion in samples prepared within the high-humidity experiment (without fluid

12 source contact) is almost three orders of magnitude lower than the samples prepared with liquid-

13 water introduction.

This diffusion behavior is caused by the water distribution exhibited by porous-rock gravel

15 (Figure 1). Rock surfaces in partially saturated environments will generally be wetted by liquid

16 films that can be held either by adsorptive forces on mineral surfaces or by capillary forces in

17 surface depressions. For a porous-rock-gravel system, the total water content is comprised of

18 surface (intergranular) water (surface film water around grains and pendular water between rock

19 grain contacts) and interior (intragranular) water (water contained within the rock matrix pores).

20 Small pores and the relatively large porosity of tuff gravel could play an important role in

21 retaining water in the internal pores, reducing the surface water content of the gravel to levels

22 where diffusion becomes as low as the detection limits of conventional methods. This interior

23 water is not likely to contribute significantly to water flow and transport in the unsaturated gravel

24 system (Conca and Wright, 1990; Tokunaga et al., 2003). Pendular water elements between gravel 
1 grains serve as the bridging pathways between grains and control the efficiency of the system in

2 attaining the upper limit of transport determined by surface films. Diffusion in rock gravel could

3 be very slow, because water films on surfaces can be discontinuous or absent. Conca and Wright

4 (1992) reported an experimental method to determine diffusion coefficients (using the Nernst-

5 Einstein equation) by using an unsaturated-flow apparatus in combination with electrical-

6 conductivity measurements. However, experimental limitations may exist with this approach,

7 such as the contact resistance at low water contact and the applicability of the Nernst-Einstein

8 equation in geologic media at very low saturation. To further understand and explore the low

9 diffusion potential in unsaturated porous gravel, we need a refinement of available testing methods

10 or the development of innovative approaches to diffusion methods.

\section{EXPERIMENTAL APPROACH}

In this work, we (1) used x-ray computed tomography (CT) to examine the flow

14 characteristics and water distribution in a tuff gravel column, (2) employed an electrical

15 conductivity approach to measure the effective diffusion coefficient of similar gravel columns, and

16 (3) examined diffusion behavior of single tuff grains inside humid environments with different

17 contacts. For this single-grain study, we employed a micro-scale mapping technique that involved

18 using laser ablation interfaced with inductively coupled plasma-mass spectrometry (LA-ICP/MS).

Tuff block samples from the Topopah Spring welded (TSw) volcanic tuff, the potential

20 repository geologic unit, were collected at the underground tunnel at Yucca Mountain, Nevada.

21 For gravel column experiments, tuff samples were crushed and sieved into various-sized fractions.

22 For the micro-scale mapping approach, tuff samples were machined into two shapes: cubic (1.50

$23 \mathrm{~cm}$ in length) and tetrahedron $(1.50 \mathrm{~cm}$ each side of the triangle and $1.30 \mathrm{~cm}$ in height). The

24 external surface roughness of these machined samples was measured using a scanning white 
UCRL-JRNL-201012

1 interferometer (Zygo Newview 200, Zygo Corporation, Middlefield, Connecticut ). The measured

2 value of the root-mean-square (RMS) roughness is $2.2 \mu \mathrm{m}$ over $714 \mu \mathrm{m}$ scans.

\section{X-Ray Computed Tomography Scanning of Tuff Gravel System}

4

5

CT scanning provides a direct view of fluid distribution in geological media. Recently, Polak et al. (2002) used an x-ray CT scanner to investigate the diffusion of NaI between a fracture and the surrounding matrix under a saturated chalk core. Interested readers are referred to the paper of Clausnitzer and Hopmans (2000) for an excellent review about the background and principles of $\mathrm{CT}$ with respect to its application in flow and transport studies.

We used CT scanning to provide a preliminary evaluation of our conceptual model about moisture distribution and flow pathways in unsaturated tuff gravel. Using the CT scanner, we were able to observe pathways available for diffusive transport. A modified medical-based x-ray CT scanner with cross-sectional resolution of $0.2 \mathrm{~mm}$ by $0.2 \mathrm{~mm}$ (Siemens Somatom HiQ, Siemens, Malvern, Pennsylvania) was used to monitor moisture distribution in sample holders packed with crushed tuff. A high-accuracy $( \pm 12 \mu \mathrm{m})$ computer-controlled positioning table was used for positioning (Tomutsa et al., 1992). This positioning table enabled back-and-forth movement of the sampler holder during the scanning process. Rapid, accurate, and repeatable positioning of the sample within the x-ray beam could be programmed to perform automated series of scans. The sample holder was constructed out of Plexiglas, had a $6.35 \mathrm{~cm}$ inner diameter (i.d.), $1.27 \mathrm{~cm}$ thickness, and was threaded at both ends.

Two different size fractions of tuff gravel, $16-25 \mathrm{~mm}$ and $6.3-9.5 \mathrm{~mm}$, were used. The tuff gravels were initially oven-dried at $60^{\circ} \mathrm{C}$. After packing the sample in the holder, a background set of scans was performed while the gravel was dry. The sample holder was placed horizontally on 
1 the CT positioning table, and cross-sectional slices were taken along the core, using an $\mathrm{x}$-ray beam

2 energy of $133 \mathrm{kV}$ with a $1 \mathrm{~mm}$ slice thickness. The sample and holder were fixed on the table

3 during the experiment, ensuring proper registration of the $\mathrm{CT}$ images at precisely the same

4 locations. Scans were performed consecutively for a total length of $3 \mathrm{~cm}$ at the middle section of

5 the column. The $6.3-9.5 \mathrm{~mm}$ sample was then saturated by pumping Nanopure water into the

6 holder. Air escaped through a small hole on the top of the sample holder. The samples were

7 submerged for a day, and then water was drained from a hole on the bottom side. When only about

8 one third of the bottom section of tuff gravel was saturated, another series of scans was performed

9 at the same locations. The difference between the wet and dry scans at each slice was used to

10 determine the moisture distribution within the sample.

\section{Diffusion Measurements by the Electrical-Conductivity Method}

As discussed above, diffusion of radionuclides in unsaturated gravel could occur (1) very

14 slowly on the solid mineral surface, (2) through water in the interconnected porosity (present

15 within the gravel grains) or (3) through water films (present on the gravel surfaces). Measuring

16 low diffusion coefficients requires long duration measurements, the ability to sample on extremely

17 small spatial scales, or an indirect approach. Calculating diffusion coefficients based on electrical

18 conductivity measurements is an indirect technique that has been accepted for diffusants in bulk

19 aqueous samples (Conca and Wright, 1992). The Nernst-Einstein equation relates the electrical

20 conductivity of a solution to the effective diffusion coefficient of an ionic diffusant:

21

$$
D_{e}=\frac{R T}{F^{2}} \frac{\delta G t}{Z C}
$$


UCRL-JRNL-201012

1 Here, $R$ is the universal gas constant, $T$ is the absolute temperature, $F$ is Faraday's constant, $\delta$ is

2 the geometric factor of the experimental cell, $G$ is the measured conductance, $t$ is the transference

3 number, $Z$ is the valence of the diffusant, and $C$ is the diffusant molar concentration.

To use this method for inference of diffusion coefficients, we must account for sources of

5 conductivity in our system. Our dry porous tuff was quite resistive, as was our sample holder.

6 Thus, we consider the connected aqueous pathways (films in particular) in an unsaturated porous

7 medium as the only electrical-current-carrying routes. We can measure a resistance and calculate

8 the diffusion coefficient. This method directly accounts for the tortuosity of the fluid pathway on

9 the gravel surface and the diffusion resistance at intergranular contacts.

A cell with four electrodes was constructed to contain tuff gravel and isolate the sample

11 from the atmosphere (Figure 2). The $6.22 \mathrm{~cm}$ inner diameter cell was constructed out of

12 transparent polyvinyl chloride tubing. Nylon endcaps were machined such that two O-rings were

13 placed between each endcap and the PVC pipe, and each endcap was fitted with a stainless-steel

14 electrode to make contact with the sample across the entire cross-sectional area of the pipe. Two

15 stainless-steel screen electrodes were placed in the center of the cell approximately $65 \mathrm{~mm}$ apart.

16 A sealable access port was placed between the two screen electrodes.

The crushed tuff used in the measurements was from the 2-4 mm fraction of tuff sample,

18 with porosity and grain bulk density of $10.5 \%$ and $2.23 \mathrm{~g} / \mathrm{cm}^{3}$ respectively. The grains were

19 shard-like, often with one dimension greater than $4 \mathrm{~mm}$. The tuff was somewhat friable, and some

20 grain breakage was observed during normal laboratory handling.

The crushed tuff was vacuum saturated in $0.5 \mathrm{~g} / \mathrm{L} \mathrm{KCl}$ solution. The three compartments

22 of the cell were filled with crushed tuff at the desired volumetric water content, ranging from full 
1 to about $10 \%$ saturation for tuff grains. Tuff was compacted into each of the cell compartments,

2 and the porosity of each of the three compartments was assumed to be equal. High water contents

3 were initially used (saturated and initial drainage), and these were attained by emplacing the

4 saturated tuff in the cell and draining the sample, using a porous ceramic drain in the cell. Further

5 tuff drainage was accomplished using an ultracentrifuge (Beckman Model L8-60M/P, Beckman

6 Coulter, Fullerton, California). To do this, portions of the saturated tuff were placed in centrifuge

7 cups and drained under specified conditions. Following the centrifugation, the tuff was placed

8 into the cell inside a glove bag maintained at high relative humidity by a beaker of warm water.

9 This was to prevent dryout of the surface layer of water on the tuff grains. Although all work was

10 performed at normal laboratory temperatures, the filled cell was placed into an incubator

11 maintained at $22{ }^{\circ} \mathrm{C}$ for several hours prior to measuring resistance, to allow for thermal

12 equilibration.

Resistance measurements were made using a GenRad 1692 Digibridge LCR meter

14 (QuadTech, Maynard, Massachusetts). The LCR meter was checked against many resistance

15 measurement systems and found reliable for the expected conditions. Prior to making

16 measurements, the meter was calibrated and the offset corrected to zero, according to the

17 manufacturer's instructions. The four electrodes from the cell were connected to the four ports of

18 the meter, and resistance (series) was recorded for the five frequencies generated by the meter

$19(100,120,1,000,10,000$, and 100,000 Hz). For high water contents, measurements were made

20 primarily at $1,000 \mathrm{~Hz}$, because the quality factor $(\mathrm{Q})$ indicated by the meter was low. (Q provides

21 an indication of the phase shift $[\mathrm{Q}=\tan$ (phase shift)] between the current and voltage

22 measurement.) The Nernst-Einstein equation requires the passive resistance (phase shift $=0$ ), thus

23 the resistance value for the frequency with the lowest $\mathrm{Q}$ was selected for diffusion coefficient

24 calculation. In many cases, alternate electrode configurations were connected to the meter, and 
1 the resistance was recorded. Using the electrode numbers from Figure 2, we made measurements

2 for some water contents in the 1144, 1122, 2233, 3344, 1234 (four electrode), 1133, and 2244

3 configurations, where 1144 indicates that Current + was connected to electrode 1 , Potential + to

4 electrode 1, Potential- to electrode 4, and Current- to electrode 4. Because both positive

5 connections were connected to one electrode and both negative connections were connected to

6 another electrode, we call this a two-electrode measurement. This allowed for an analysis of two-

7 and four-electrode measurement techniques.

8 Diffusion Measurements by Micro-Scale Mapping Method

Laser ablation refers to the process in which an intense burst of energy delivered by short

11 laser pulses is used to vaporize a minute sample (i.e. in the range of nanograms) from a specific

12 location of a sample. The chemical composition of the vaporized sample is then analyzed with

13 inductively coupled plasma-mass spectrometry (ICP-MS). Laser ablation, coupled with ICP-MS

14 (LA/ICP-MS), has recently evolved as a powerful analytical tool for solid sampling (Russo et al.,

15 2000). LA/ICP-MS can determine simultaneously a large number of chemical elements with very

16 low detection limits. The high spatial resolution (i.e. in the range of microns) achieved by a

17 focused laser beam makes LA/ICP-MS a very attractive tool for slow diffusion processes.

18 A detailed study, reported in Hu et al. (2001), was conducted to evaluate the potential of

19 the LA/ICP-MS approach to direct measurement of diffusion coefficients, both at rock surfaces

20 and the interior of rock matrix. The study included choosing appropriate tracers, probing elements

21 intrinsic to tuff that can serve as internal standards to correct for different LA/ICP-MS conditions,

22 and evaluating the mapping technique.

We used a laser ablation system (CETAC LSX-200, CETAC Technologies, Omaha,

24 Nebraska) interfaced with an ICP-MS (VG-PQ3 Spectrometer, VG Elemental, Franklin, 
1 Massechusetts) with a range of spot sizes (ranging from $25 \mu \mathrm{m}$ to $350 \mu \mathrm{m}$ ). The spot size dictates

2 the spatial resolution during the surface mapping, and number of laser pulses determines the 3 amount sampled; a combination of spot size and number of laser pulses could be made to meet

4 different research objectives. A smaller spot size will, under the same number of laser pulses,

5 sample less solid material, leading to lower analytical precision. Additionally, for heterogeneous

6 samples, using a smaller spot results in more observed heterogeneity. The tuff consists largely

7 ( 99 vol. \%) of the former glassy matrix now devitrified to fine crystals of cristobalite, alkali

8 feldspar, and quartz of 3-10 $\mu \mathrm{m}$ size fractions, as shown from the scanning electron microscopy

9 analysis (Johnson et al., 1998). We primarily used a larger (100 or $200 \mu \mathrm{m})$ spot size for

10 representative sampling, with measured relative standard deviation about $10-15 \%$.

11 Evaluation from many tests indicates that, among all the intrinsic tuff elements, aluminum

12 (Al) consistently exhibits the best signal stability (i.e., least heterogeneity). Therefore, we use Al

13 for the ratio approach (dividing the response of the element of interest [the tracer chemical in this

14 case] by the response of $\mathrm{Al}$ ) to provide a normalized response that corrects any uncertainty related

15 to LA/ICP-MS. This uncertainty could include, for example, less mass ablation as the sampling

16 depth increases or possible energy fluctuations of the laser. To investigate the effect of intergrain

17 contact and relative humidity (hence thickness and continuity of surface water films), we designed

18 diffusion measurements with contact treatments of different rock-grain geometries (cube and

19 tetrahedron) inside several RH chambers (e.g., 43, 76, 93, 98, and nearly 100\%). The RH values of

$2043,76,93$, and $98 \%$ were controlled and maintained with saturated salts of $\mathrm{K}_{2} \mathrm{CO}_{3}, \mathrm{NaCl}, \mathrm{Na}_{2} \mathrm{SO}_{4}$,

21 and $\mathrm{CaSO}_{4}$, respectively. The higher (near 100\%) relative humidity was maintained by the

22 evaporation from water beakers inside the enclosed chamber. Different intergrain contact points

23 will help us understand the role of pendular water elements and water film continuity in

24 affecting/controlling diffusion pathways. Different RH conditions are used to simulate the 
1 scenarios of transient RH environments inside the drifts following the emplacement of waste

2 packages. Both water film thickness and continuity are closely related to RH conditions and

3 hence to potential diffusive radionuclide transport.

A half-element (source-sink) approach was used for diffusion measurement of unsaturated

5 tuff gravel (Figure 3). The half-element design is based on the half-cell concept, wherein each cell

6 is of the same geometry, which is commonly used for diffusion measurements (e.g., Shackelford,

7 1991; Flury and Gimmi, 2002). In the half-element approach, a source element (a tuff cube in this

8 work) containing a tracer was placed in contact with a sink element (either a cube or a

9 tetrahedron) not containing the tracer, both under the same temperature and RH. The tracer will

10 then diffuse from the tracer-containing element to the other, and its diffusion coefficient is

11 obtained from the concentration profile at different locations at a certain diffusion time.

12 The source tuff cube was vacuum-saturated with a tracer mixture solution that contained

13 bromide $\left(\mathrm{Br}^{-}\right)$and perrhenate $\left(\mathrm{ReO}_{4}{ }^{-}\right)$. Both species act as nonsorbing tracers, confirmed from our

14 laboratory column transport experiments using crushed tuff. Perrhenate serves as an analog to

15 technetium (Brookins, 1986), which in the form of pertechnetate $\left({ }^{99} \mathrm{TcO}_{4}{ }^{-}\right)$is of concern for the

16 potential repository at Yucca Mountain. Cationic sorbing tracers $\mathrm{Cs}^{+}, \mathrm{Co}^{2+}, \mathrm{Sr}^{2+}$, and $\mathrm{Sm}^{3+}$, as the

17 counter ions for the nonsorbing anions in the tracer solution, were chosen to examine the

18 combined transport from unsaturated diffusion and retardation. This paper is, however, focused on

19 the behavior of nonsorbing tracers.

The sink element was also vacuum-saturated, but without tracers. Source and sink

21 elements were then separately placed inside a humidity chamber within an incubator maintained at

$22 \quad 22^{\circ} \mathrm{C}$. Cube weight was periodically monitored until it reached a constant weight. This pre-

23 equilibration, which takes 137 days for the lowest $\mathrm{RH}$ of $43 \%$, is to ensure an establishment of 
1 similar water potential between source- and sink-element to prevent/minimize potential advective

2 transport. The elements were then placed in a customized sample holder, clamped together, and

3 placed in the RH chamber to start the diffusion test (Figure 3). For the cube-tetrahedron geometry,

4 a cube face was in contact with an apex of the tetrahedron, resulting in a point contact between the

5 elements. After a certain diffusion duration, the diffusion test was stopped by separating the

6 source and sink elements. Tracer distributions on the tuff surface were immediately mapped using

7 LA/ICP-MS. After mapping the sink cubes, a small groove was hand-sawed in the middle of the

8 top face parallel to the diffusion direction, and the cube was cracked open with a hammer and a

9 chisel to expose the interior. The interior surface was then mapped by adjusting the laser focus at

10 each sampling location for the exposed rough surface. Stable responses were obtained during

11 testing of these tuff elementsdespite the rough surface (Hu et al., 2001).

\section{RESULTS AND DISCUSSION}

\section{CT Imaging of Tuff Gravel}

Figure 4 shows twelve consecutive $1 \mathrm{~mm}$ thick cross-sectional images for $16-25 \mathrm{~mm}$ and

$15 \quad 6.3-9.5 \mathrm{~mm}$ tuff gravels. Very little physical contact is observed between the tuff grains for the

$16 \quad 16-25 \mathrm{~mm}$ size fraction, while noticeable, limited contact exists for the smaller size gravel. The

17 measured bulk density was 0.549 and $0.806 \mathrm{~g} / \mathrm{cm}^{3}$ for the column packed with $16-25 \mathrm{~mm}$ and

$18 \quad 6.3-9.5 \mathrm{~mm}$ gravels, respectively. Transport pathways in such gravel systems could be

19 significantly hindered because of the limited number of contact locations between grains.

A series of CT images are shown in Figure 5a for partially saturated 6.3-9.5 mm gravel.

21 Water pockets (purple color in Figure 5a) are easily discerned in the scans from air and tuff grains.

22 Subtraction of a set of dry scans from the wet background scans is shown in Figure $5 \mathrm{~b}$ to indicate 
1 the water distribution. In these images, only the difference between the two conditions (dry and

2 wet) is observed. Some water is shown in the nonsubmerged top part (Scan No. 1 of Figure 5b),

3 and this is probably caused by the water pooling on the top of the flat grains. Also, tuff grains in

4 the top portion are not totally subtracted out, probably because of the slight movement of grain

5 position from water introduction and drainage. A slight positioning error is also apparent as the

6 sample holder outline is slightly visible. Outlines of individual grains may be enhanced similarly.

\section{Diffusion Measurements by Electrical Conductivity Method}

$8 \quad$ Measured diffusion coefficients

9 We have measured the resistance of partially saturated crushed tuff gravel occupying a cell

10 with known dimensions. The tuff was conditioned with preset water contents and the water

11 contained a known concentration of potassium chloride. Using the measured resistance and

12 known geometry, we have calculated effective diffusion coefficients $D_{e}\left(\mathrm{~L}^{2} \mathrm{~T}^{-1}\right)$, which

13 incorporate the effect of the geometry of the grains and their contacts, and the liquid content of the

14 unsaturated system on diffusion.

15 The diffusion coefficients calculated using the Nernst-Einstein equation for volumetric

16 moisture content are shown in Figure 6 and Table 1. The five points with volumetric water

17 content greater than $5.4 \%$ were attained by drainage of the initially brine saturated cell.

18 Volumetric water contents below 5.4\% were achieved by centrifuging vacuum-saturated tuff at

$191,000,2,000,3,000,4,000$, and 8,000 revolutions per minute (rpm) in an ultracentrifuge prior to

20 placing it in the cell. The tuff surface appeared to become progressively drier as the centrifuge

21 speed increased. Any handling of the tuff resulted in some breakage. Centrifugation at 8,000 rpm

22 resulted in a high amount of smaller particles being generated (and a higher packing density in the 
UCRL-JRNL-201012

1 cell), which could result in a higher diffusion coefficient. In a similar study, tuff was also

2 observed to disintegrate, with sharp angular points breaking down, at centrifuge speed larger than

$36,000 \mathrm{rpm}$ (CRWMS M\&O, 2000a).

The calculated diffusion coefficients were compared to those presented by Conca and

5 Wright (1990) and to the data presented by OCRWM M\&O (2000a), all obtained from EC measurements. At moisture contents larger than 5.5\%, our results agree very well with previous

7 measurements and the power-law-curve fit. However, at lower moisture contents, our results tend

8 towards lower diffusion coefficients than the power-law curve fit. In our measurements, the lowest

9 volumetric water content we achieved was about 5\% (on a cell volume basis). The volumetric

10 water content declined only slightly on a tuff grain basis as the centrifuge speed was increased for

11 enhanced drainage. It is probable that this slight reduction in water content comes from the

12 surface films and pendular elements. These slight changes, however, resulted in an increased

13 measured resistance and a decreased calculated diffusion coefficient, without any apparent

14 decrease in volumetric water content (cell basis). This is consistent with the unique behavior of

15 water distribution in porous tuff, as discussed above.

Evaluation of the electrical conductivity approach

Extending the application of the Nernst-Einstein equation to diffusion in unsaturated

18 porous media requires several assumptions. We first must assume that the water films are thick

19 enough to act as bulk water. Nearest the mineral surface, the water molecules will be relatively

20 fixed (unlike bulk water). Ions opposite in charge to the surface charge will be concentrated near

21 the surface, while similarly charged ions will be repelled from the surface. In very thin water

22 films, both of these layers will be compressed towards the mineral surface. The higher viscosity

23 of the water molecules on the solid surface will lead to slower diffusion, because the diffusivity of 
1 ions in water is inversely proportional to the viscosity of the water. Kemper (1960) showed that

2 the viscosity of the first three layers of water sorbed on Na-saturated mineral surfaces was about

3 10, 1.6, and 1.1 times, respectively, that of bulk water. van Olphen (1965) (cf., Stewart, 1972)

4 reports that for montmorillonite the matric potentials needed to desorb the fourth, third, second,

5 and first layers of adsorbed water are about 200, 1,200, 2,500, and 5,400 bars respectively. Stewart

6 (1972) extrapolated the fifth and sixth layer of adsorbed water to be in the region of 30 to 50 bars.

7 The equivalent matrix potential under our centrifugation condition at $8,000 \mathrm{rpm}$ is 13.4 bars;

8 therefore, the effects of water structure on slow diffusion are not expected to be significant.

9 One important requirement for the use of the Nernst-Einstein equation is that the mode of

10 electrical conduction must be known. That is, to use the Nernst-Einstein equation to calculate

11 diffusion coefficients in an aqueous system, there must be an understanding of the contribution to

12 total electrical conduction from various possible modes of current conduction. If other modes of

13 current conduction are present (such as through the mineral, on the dry mineral surface, through

14 adsorbed water on the mineral surface, through the intragranular pore space, or at the grain/grain

15 connections), the Nernst-Einstein equation may not be applicable, or these individual effects may

16 require quantification. Our system used a hydrophobic, resistive sample holder, and the resistivity

17 of air is high, allowing us to eliminate these current pathways. Attempts to measure the resistivity

18 of air-dry tuff failed because of the high resistivity, leaving bulk water and surface conduction as

19 the only conductivity pathways.

Other concerns include electrode design, electrode/sample polarization, and contact

21 impedance at the electrode/sample interfaces. These problems can be minimized by constructing

22 optimally sized and shaped sample holders and by performing experiments on samples in which

23 electrode spacing is the only variable. We assess the effects of electrode-contact impedance by 
1 making measurements with a four-electrode configuration and multiple two-electrode

2 configurations. When a four-electrode configuration is used, current is applied across the outer

3 electrodes and potential is measured across the inner electrodes. In the wires and electrodes,

4 current is carried by electrons; in the water-rock system, current is carried by ions. This change in

5 charge carrier from electronic to ionic occurs at the current electrode/rock interface and results in

6 contact impedance. The inner electrodes measure only the potential, and since very little current

7 is drawn from the system to make this measurement, there is no contact impedance at these

8 electrodes. Calculating the resistance between the potential electrodes can then be accomplished

9 without the influence of contact impedance. Using the two-electrode configuration, current is

10 applied and potential is measured at the same two electrodes. Thus, any contact impedance is

11 included in the resistance calculation. This contact impedance was minimal at high volumetric

12 water contents, but increased to as much as $5 \%$ of the indicated resistance in the drier

13 measurements. However, the effect of surface water connectivity on diffusion is so predominant

14 that such refinement yields similar results (shown in Figure 6), to those done by others in which a

15 two-electrode design is used.

An additional concern with electrode-sample contact is that for the Nernst-Einstein

17 equation to apply, a passive resistance (near-zero phase angle) was required. As the sample water

18 content changed, the frequency providing the most passive resistance (smallest phase angle) also

19 changed. Conca and Wright (1992) used a fixed impedance of $1,000 \mathrm{~Hz}$ for their two-electrode

20 configurations. For most of our two-electrode measurements, we confirmed that $1,000 \mathrm{~Hz}$ was the

21 best of the five frequencies available on the GenRad 1692. For the four electrode measurements,

22 however, 100 and $120 \mathrm{~Hz}$ provided more passive resistances. The geometry of the measurement

23 cell also affected the phase shift. Values of Q close to zero were obtained across a wider 
1 frequency range $(1,000 \mathrm{~Hz}-10,000 \mathrm{~Hz})$ for the two electrode measurements across the entire cell,

2 whereas for the shorter intervals, frequencies near $1,000 \mathrm{~Hz}$ were required.

It is appropriate to ask what effects grain size and internal porosity have. The effect of

4 grain size has not been adequately investigated. All of our specimens had nominally the same

5 grain size. Much larger volumes would be necessary for larger gravel sizes. With these larger

6 grain sizes, it would be difficult to establish the appropriate moisture conditions and

7 representatively measure both resistance and physical properties to the accuracy needed. An

8 ultracentrifuge might limit preparation to three grains at a time, and the use of relative humidity

9 chambers would require the very slow transfer of large amounts of mass. Under similar

10 thermodynamic conditions, smaller grains provide larger surfaces. If we assume that the surface

11 film controls the electrical conduction (and thus the diffusivity), smaller grains should provide less

12 diffusive resistance.

\section{Diffusion Measurements by Micro-Mapping Method}

\section{Evaluation of testing technique}

15 During our preliminary experiments for measuring unsaturated diffusion in a cube-cube

16 configuration in the nearly $100 \% \mathrm{RH}$ chamber, the diffusion time was as long as 150 days, based

17 on our sample length $(1.5 \mathrm{~cm})$ and a diffusion coefficient of smaller than $10^{-15} \mathrm{~m}^{2} / \mathrm{s}$, as inferred by

18 Conca (1990) from the detection limit of resistance. Our measurements of tracer concentration

19 indicate that diffusion coefficients are higher under similar RH conditions.

Figure 7 shows the tracer distribution and comparison for both the source and sink cubes

21 from an experiment in which two cubes were placed side by side in a nearly $100 \% \mathrm{RH}$ container

22 for 150 days. Nonsorbing tracers $\left(\mathrm{Br}^{-}\right.$and $\left.\mathrm{ReO}_{4}{ }^{-}\right)$are evidently present across almost the entire 
UCRL-JRNL-201012

1 sink cube face (Face 3) perpendicular to the interface face (i.e., in the direction of surface

2 diffusion). Distribution of diffusive tracers is corroborated from the results on the far-side face of

3 the sink cube, where both $\mathrm{Br}^{-}$and $\mathrm{ReO}_{4}{ }^{-}$are detected. As expected, the tracer distributions on the

4 far-side face of the source cube are more uniform and at much higher (about 10 times)

5 concentrations than the sink cube. Furthermore, the interface faces have similar tracer

6 concentration distributions for both the source and sink cubes, indicating good contact and

7 diffusive mass transfer between cubes. An edge effect (an unusually low concentration at several

8 millimeters distance from the cube edge near the far-side face) was noticed. The cause is not clear,

9 but it may possibly be related to the thin Teflon sheet placed between the far-side face and acrylic

10 sample holder. The Teflon sheet provided a nonwetting barrier to aqueous diffusion in the half-

11 element diffusion setup.

12 Measured diffusion coefficients

13 An appropriately short diffusion time was then selected for different experimental setups,

14 with longer time for lower RH tests (Table 2). Figure 8a shows the mapped tracer distribution for

15 cube-cube configuration exposed to a $98 \% \mathrm{RH}$ environment, which exhibits a typical diffusion

16 profile across the interface $(\mathrm{X}=0 \mathrm{~cm})$. Intensity of tracer response is plotted in log scale on the $\mathrm{Y}$ -

17 axis, contrary to the typical diffusion profile in arithmetic scale reported by others, because of the

18 high sensitivity of ICP/MS. It appears that the diffusion front reaches about $1 \mathrm{~cm}$ and $0.1 \mathrm{~cm}$ for

19 both tracers in the $98 \% \mathrm{RH}$ and $43 \% \mathrm{RH}$ tests, respectively. After this distance, the signals

20 essentially show the background response. The background response for $\mathrm{Br}^{-}$is higher than that for

$21 \mathrm{ReO}_{4}^{-}$, because of its lower sensitivity by ICP/MS analysis. Nevertheless, we obtained a diffusion

22 profile with a signal spanning more than two orders of magnitude for $\mathrm{Br}^{-}$, compared to three orders 
UCRL-JRNL-201012

1 for $\mathrm{ReO}_{4}^{-}$, to provide us with a high-resolution value of the diffusion coefficient obtained from the

2 profile.

In the half-element configuration and for an infinite system in which the concentration

4 profile does not reach the ends of the element, the analytical solution to the transient diffusion

5 equation (Fick's second law) is as follows (Crank, 1975; Flury and Gimmi, 2002):

6

$$
\frac{C}{C_{0}}=\frac{1}{2} \operatorname{erfc} \frac{x}{2 \sqrt{D e \times t}}
$$

7 where $C\left(\mathrm{M} \mathrm{L}^{-3}\right)$ is the observed concentration at location $x$ based on an initial concentration $C_{0}$

$8 \quad\left(\mathrm{M} \mathrm{L}^{-3}\right), x(\mathrm{~L})$ is the distance from the interface boundary into the sink element, and $t(\mathrm{~T})$ is the 9 diffusion time.

Figure 9 shows examples of curve-fitting of the obtained tracer concentration profiles; with

11 Figure 9a presenting a sensitivity analysis of varying $D_{e}$. The fitted diffusion coefficients for

12 different half-element configuration under a RH environment are listed in Table 2. The diffusion

13 of $\mathrm{Br}^{-}$is relatively faster than $\mathrm{ReO}_{4}{ }^{-}$, as expected from its larger aqueous diffusion coefficient

$14\left(D_{0}\right) ; 2.08 \times 10^{-9} \mathrm{~m}^{2} / \mathrm{s}$ for $\mathrm{Br}^{-}$and $1.46 \times 10^{-9} \mathrm{~m}^{2} / \mathrm{s}$ for $\mathrm{ReO}_{4}{ }^{-}(\mathrm{Lide}, 2000)$. The ratio of measured

$15 D_{e}$ for $\mathrm{Br}^{-}$to $\mathrm{ReO}_{4}{ }^{-}$is also presented in Table 2, with an average of 1.81 and a standard deviation

16 of 0.65 , compared to their $D_{0}$ ratio of 1.42 . This comparison confirms that diffusion is the

17 predominant, and likely the only, mode of transport in our experimental systems, as we intended

18 to achieve. For cube sinks, a boundary zone of a few millimeters appears to exist with a lower

19 concentration (higher diffusion) than the overall pattern. This might be related to the boundary

20 condition of the half-element configuration, since we do not see such an edge effect for the

21 tetrahedron sink sample (Figure 9b), where the fitted diffusion curve captures all data very well. 
UCRL-JRNL-201012

Using RH to establish moisture content provides us with multiple water saturations and a

2 relevant scenario to the waste package emplacement drifts. The bulk liquid saturation, and hence

3 volumetric water content, is closely related to the RH environment. As the RH decreases, the

4 diffusion coefficient decreases dramatically (Table 2). These measured data deviate from the

5 "universal" power-law fit for diffusion as a function of water content, especially at the lower RH

6 treatments, though the water saturations are still high (Figure 6). The two approaches, EC and

7 micro-scale mapping, give overlapping diffusion coefficient. The advantage of EC technique is

8 that it provides a relatively fast measurement of diffusion as a function of water saturation. The

9 micro-scale mapping approach complements with the EC technique in obtaining a diffusion value

10 as low as $10^{-14} \mathrm{~m}^{2} / \mathrm{s}$ under lower water contents.

11 Hu and Wang (2003) reviewed the behavior of, and relationship between, nonsorbing

12 diffusants and water content, particularly for porous aggregates (e.g., rock gravel). Diffusion is

13 monotonically related to water content, but the relationship is not simple and depends upon the

14 range of water content (i.e., different forms of relationships at different water-content ranges).

15 The relationship is also related to the texture and characteristics (e.g., surface wettability) of the

16 geologic medium. It is evident that the water content at which deviation occurs is different among

17 the tuffs and silica sand (Figure 6), which is probably related to the sample size used and the

18 difference in porosity and surface wettability.

19 Surface diffusion

20 In our investigations, we used 10 or 20 laser pulses to map tracer concentration

21 distributions at different locations. A single laser pulse creates a crater with a depth of about 0.83

$22 \mu \mathrm{m}$, obtained from multiple measurements using a polished tuff sample with a RMS surface

23 roughness of $0.28-0.35 \mu \mathrm{m}$ (from four $714 \mu \mathrm{m}$ long scans). Twenty laser pulses, having a 
1 corresponding sampling depth about $16 \mu \mathrm{m}$, were used for the tracer mapping on the gravel

2 surface from which the diffusion coefficients was obtained in Table 2. The unpolished tuff

3 elements used in the diffusion tests have a measured surface roughness about $2.2 \mu \mathrm{m}$, which

4 indicates the topographic constraint on water film thickness (Tokunaga et al., 2003).

5 Tokunaga and coworkers used a synchrotron x-ray fluorescence technique, which has a 6 quantification limit of $0.3 \mu \mathrm{m}$, to measure a range of water film thickness for glass, natural rock

7 and gravel samples. Tokunaga and Wan (1997) reported that an average surface film thickness for

8 a Bishop Tuff fracture surface with a roughness $\sim 50 \mu \mathrm{m}$ ranged from 2 to $70 \mu \mathrm{m}$ at matrix

9 potential greater (more positive) than about $-250 \mathrm{~Pa}$ (with corresponding $\mathrm{RH}>99.999 \%$,

10 according to the Kelvin equation). Average film thickness on a roughened glass (with a surface

11 roughness of about $9 \mu \mathrm{m}$ ) was between $1.0 \mu \mathrm{m}$ to $2.3 \mu \mathrm{m}$ (Tokunaga et al., 2000). This was

12 measured under matric potentials of $-20 \mathrm{kPa}$ and $-1.2 \mathrm{kPa}$, which correspond to $\mathrm{RH}$ exceeding

$1399.9 \%$. With gravel samples from Hanford, Washington, Tokunaga et al. (2003) reported average

14 film thicknesses of $7-10 \mu \mathrm{m}$ at near-zero (-0.05 to $-0.10 \mathrm{kPa})$ matric potentials. Under drier

15 conditions, they expect that the smooth surfaces of natural Hanford gravels cannot support thick

$16(>2 \mu \mathrm{m})$ water films for fast advective flow, and chemical transport will be diffusion-limited. Our

17 diffusion experiments were conducted at drier conditions than reported above.

The effects of RH conditions and sample wettability (hydrophobicity) are very critical for

19 surface film thickness. Using an ellipsometric technique, Gee et al. (1990) determined the

20 equilibrium water film thickness on quartz as a function of relative vapor pressure. (The natural

21 crystalline quartz plates used were polished with a RMS surface roughness of $10 \AA$.) They also

22 evaluated the effect of wettability of film thickness by dehydroxylating the quartz samples from

23 heating treatments. Some of their results are reproduced here in Figure 10. It is not until the 
UCRL-JRNL-201012

1 system nears saturation $(\mathrm{RH}>90 \%)$ that the film thickness undergoes a sharp increase indicative of

2 the formation of multilayers of water on the quartz surface (Figure $10 \mathrm{a}$ ). In contrast, the

3 magnitude of the film thickness on heat-treated quartz is much lower (Figure 10b). Another

4 feature of the dehydroxylated quartz is that film thickness does not increase monotonically with

$5 \mathrm{RH}$, but seems to fluctuate and displays a distinct step at $\mathrm{RH}$ of $80 \%$. The films are metastable at

6 small film thickness (Gee et al., 1990).

We are not aware of any reports on contact angle measurement for tuff samples at Yucca

8 Mountain, but the tuff is water wetting because water drops immediately spread over the tuff

9 surface. However, our measured diffusion coefficients seems to decrease significantly at RH less

10 than $93 \%$ (Table 2), similar to the deflection point of surface water film at $90 \% \mathrm{RH}$ observed for

11 the fully water-wetting quartz (Gee et al., 1990). In a lower RH environment, the diffusion

12 coefficient becomes even smaller; the values are more than three orders of magnitude smaller at

13 the $\mathrm{RH}$ of $43 \%$ than that of $98 \%$. This is likely related to the effect of surface film thickness on the

14 magnitude of diffusion. Furthermore, it seems that the importance of surface film thickness is

15 more critical than the extent of contact, because diffusion values for cube-tetrahedron are similar

16 to cube-cube contact at the same RH condition (Table 2).

Other resistivity measurements in the unsaturated tuff of Yucca Mountain lend evidence of

18 water configuration at different saturations and its role in controlling flow pathways. Roberts and

19 Lin(1997) reported water existing in three configurations as a function of water saturation. These

20 configurations are adsorbed water on solid surfaces (Region 1, from completely dry to $\sim 15 \%$

21 saturation), isolated pockets of water (Region 2, in the saturation range of $\sim 15$ to $35 \%$ ), and

22 continuous (bulk) water (Region 3, from $\sim 35$ to 100\% saturation). Region 1 has the steepest drop

23 in resistivity as saturation increases, and conduction is assumed to be primarily through layers of 
1 adsorbed water. From the measured porosity and surface area/volume reported in Roberts and Lin

2 (1997), we calculate that the average water-film thickness is about $115 \AA$ at the water saturation of

$315 \%$. This calculation supports the importance of a connected water film on resistivity and

4 diffusion at this range of low water content. Region 2 is comprised of pendular rings at grain

5 contacts and pore-throat constrictions, and is physically separated by air. The transition from

6 Region 2 to Region 3, which might correspond to $\mathrm{RH}>93 \%$ in this study, is less abrupt and

7 indicates a gradual displacement of air in the pore space.

8 Interior diffusion

9 The interior diffusion could be composed of pore-water diffusion (diffusion in relatively

10 large, interconnected water-filled pores and microcracks), grain-boundary diffusion (aqueous

11 diffusion through relatively small pore spaces such as grain boundaries), or intracrystalline

12 diffusion in minerals. Grain boundaries usually contain thin water films on their surfaces, and

13 diffusion through thin intragranular water films in well-consolidated rocks is often much slower

14 than pore-water diffusion because the structure of the thin water film may be more constrained

15 from interaction with solids than "free" water in pores. From compiled literature data for many

16 types of rock, Nakashima (1995) reported that grain-boundary diffusivity is less than $10^{-15} \mathrm{~m}^{2} / \mathrm{s}$,

17 and the ratio of pore-water to grain-boundary diffusion is on the order of 100 to 1,000 . However,

18 Kozaki et al. (2001) reported that grain-boundary diffusion was the predominant diffusion process,

19 even for anions like chloride, in saturated montmorillonite. Intracrystalline diffusion will be even

20 slower because of the extremely constricted diffusion through narrow channels within the crystal

21 structure. For example, Rundberg (1987) estimated, from kinetic sorption data, that

22 intracrystalline diffusion coefficients in partially welded devitrified tuff from the Prow Pass unit at

23 Yucca Mountain ranged from $1.1 \times 10^{-19}$ to $6.7 \times 10^{-17} \mathrm{~m}^{2} / \mathrm{s}$ for cesium, strontium, and barium. 
For cube sinks, tracer concentrations for both surface and interior of the tuff cube are

obtained in this study. In all RH tests, there is little difference for the measured diffusion coefficients between the surface and interior. At high $\mathrm{RH}$ environments $(>76 \%)$, the interior diffusion in the tuff is probably controlled by the pore-water type. The transition from pore-water diffusion to the grain-boundary diffusion occurs at lower RHs. It is likely that the diffusion at $43 \%$ $\mathrm{RH}$ is predominantly influenced by the grain-boundary water.

The utility of diffusivity tracers with different molecular sizes helps us evaluate the steric hindrance effect on diffusion within narrow pores. This pore-size restriction effect is not evident among $\mathrm{Br}^{-}$and $\mathrm{ReO}_{4}{ }^{-}$, with $\mathrm{ReO}_{4}{ }^{-}$being a larger molecule. In saturated rock-beaker diffusion tests measuring tracer concentration change in tuff cavity (i.e., beaker), Triay et al. (1997) suspected this exclusion effect for $\mathrm{TcO}_{4}^{-}$. Instead of monitoring the concentration change in the liquid reservoir as in conventional diffusion tests, we directly measure the concentration of two diffusivity tracers in rock samples to examine the potential exclusion effect. A significant steric hindrance effect is expected when pore diameter is less than 10 times the molecular diameter (Grathwohl, 1998). Using mercury porosimetry, Roberts and Lin (1997) reported that the average matrix pore diameters (weighted by increments of pore space filled) for welded and densely welded Topopah Spring tuff samples at Yucca Mountain are 53.1 nm and 19.7-21.4 nm, respectively. From the weight-gain measurements on core saturation of densely welded TSw samples inside controlled relative-humidity chambers, we found that about $10 \%$ of tuff pores were smaller than $10 \mathrm{~nm}$. The effective ionic diameters for $\mathrm{Br}^{-}, \mathrm{ClO}_{4}{ }^{-}$, and $\mathrm{TcO}_{4}{ }^{-}$are $0.390,0.472$, and $0.480 \mathrm{~nm}$, respectively (Neck and Kanellakopulos, 1987). Given its similar structure, the diameter of $\mathrm{ReO}_{4}{ }^{-}$is probably similar to $\mathrm{ClO}_{4}{ }^{-}$and $\mathrm{TcO}_{4}{ }^{-}$. Based on the above information, the pore-size restriction in the tuff matrix is not expected to have a significant impact on the diffusive processes for these tracers, as confirmed by experimental results. 
UCRL-JRNL-201012

\section{CONCLUSIONS}

In this work, innovative and complementary approaches are employed to investigate and characterize the unsaturated diffusion processes in porous gravel. At unsaturated conditions, aqueous diffusion occurs in liquid films on the gravel surfaces, and the diffusion will be very slow if the water film is thin and discontinuous. Diffusion in unsaturated gravel is not solely dependent upon the magnitude of water content; rather it is more closely related to the thickness, mobility, and continuity of the surface water. Within porous rock gravel, appreciable water can exist as surface film around the grain without significantly contributing to overall diffusion, because this water is structurally constrained.

At Yucca Mountain, unsaturated porous tuff gravel could serve as a diffusion and transport barrier because of its water-distribution characteristics. During relatively low RH environments such as the time period following heating phase from radionuclide decay, surface water films are expected to be thin, discontinuous, or completely removed. Diffusive transport of radionuclides in such systems will be greatly reduced. Additionally, the thermal history of a mineral affects its wettability, with heat-treated quartz samples being more hydrophobic than nonheat-treated samples at a temperature of $1,050{ }^{\circ} \mathrm{C}$ (Gee et al., 1990). This thermal effect could impact diffusion through a gravel invert. Porous tuff gravel can, however, hold a considerable amount of water within grains because of its large capillary force. It can imbibe liquid from seepage or breached waste packages to minimize drainage of radionuclides through the invert gravel. This unique capacity of porous gravel can be harnessed to maximize the performance of the potential repository.

2 Currently used diffusion models relating diffusion coefficients to total volumetric water content inadequately describe the bimodal diffusion behavior in porous gravel. The "universal" 
1 curve does not capture the unique characteristics of water distribution for gravel. The distribution

2 of water in gravel (containing both surface and interior water) is analogous to that of a fracture-

3 matrix water system, and a dual-continuum approach could be used to model the diffusion

4 behavior. Considering the importance and recent recognition of gravel in waste management and

5 environmental remediation, such a dual-diffusivity model approach is necessary.

\section{ACKNOWLEDGMENTS}

7 This work was supported by the Director, Office of Civilian Radioactive Waste Management, U.S.

8 Department of Energy, through Memorandum Purchase Order EA9013MC5X between Bechtel

9 SAIC Company, LLC, and the Ernest Orlando Lawrence Berkeley National Laboratory (LBNL),

10 and Lawrence Livermore National Laboratory (LLNL). The support is provided to LBNL through

11 the U.S. Department of Energy Contract No. DE-AC03-76SF00098, and to Lawrence Livermore

12 National Laboratory under contract No. W-7405-Eng-48. We greatly appreciate the help from

13 Andrew Mei for rock machining, Ingrid Zubieta for laboratory assistance, Xiang-Lei Mao and

14 Jhanis Gonzalez of LBNL for their insightful discussions and operation related to LA/ICP-MS,

15 and Steven Carlson of LLNL for helpful discussions about electrical conductivity. The authors

16 also thank Christopher Campbell and Daniel Hawkes of LBNL for many helpful comments. 
UCRL-JRNL-201012

\section{REFERENCES}

Brookins, D.G. 1986. Rhenium as analog for fissiogenic technetium: Eh-pH diagram $\left(25^{\circ} \mathrm{C}, 1\right.$ bar) constraints. Appl. Geol., 1:513-517.

Clausnitzer, V., and J.W. Hopmans. 2000. Pore-scale measurements of solute breakthrough using microfocus X-ray computed tomography. Water Resourc. Res., 36(8):2067-2079.

Conca, J.L. 1990. Diffusion barrier transport properties of unsaturated Paintbrush tuff rubble backfill. Proceedings of the First International High-Level Radioactive Waste Management Conference, 1: 394-401.

Conca, J.L. and J. Wright. 1990. Diffusion coefficients in gravel under unsaturated conditions. Water Resour. Res., 26(5): 1055-1066.

Conca, J.L. and J. Wright. 1992. Diffusion and flow in gravel, soil, and whole rock. Appl. Hydrogeo., 1: 5-24.

Crank, J. 1975. The Mathematics of Diffusion. 2nd ed., Oxford University Press Inc., New York.

CRWMS M\&O (Civilian Radioactive Waste Management System Management and Operating Contractor). 2000a. The Determination of Diffusion Coefficient of Invert Materials. TDREBS-MD-000002 REV 00. Las Vegas, Nevada.

CRWMS M\&O. 2000b. Invert Diffusion Properties Model. ANL-EBS-MD-000031 REV 01. Las Vegas, Nevada.

Flury, M., and T.F. Gimmi. 2002. Solute Diffusion. pp. 1323-1351. Chapter 6.2 In Methods of Soil Analysis. Part 4 - Physical Methods. J.H. Dane and G.C. Topp (eds.). Soil Sci. Soc. Am., Madison, Wisconsin. 
UCRL-JRNL-201012

1 Gee, M.L., T.W. Healy, and L.R. White. 1990. Hydrophobicity effects in the condensation of water films on quartz. J. Colloid Interface Sci., 140(2): 450-465.

3 Grathwohl, P. 1998. Diffusion in Natural Porous Media: Contaminant Transport, 4 Sorption/Desorption and Dissolution Kinetics, Kluwer Academic Publishers, Boston, MA.

5 Hu, Q., T. Kneafsey, J.S.Y. Wang, J.J. Roberts, and S. Carlson. 2001. Summary report on Phase 1 6 feasibility study of in-drift diffusion. LBNL-49063, Lawrence Berkeley National Laboratory, $7 \quad$ Berkeley, CA.

$8 \mathrm{Hu}$, Q., and J.S.Y. Wang. 2003. Aqueous-Phase diffusion in unsaturated geological media: A 9 review. Critical Reviews in Environmental Science and Technology, 33(3):275-297.

10 Johnson, J.W., K.G. Knauss, W.E. Glassley, L.D. DeLoach, and A.F.B. Thompson. 1998.

11 Reactive transport modeling of plug-flow reactor experiments: quartz and tuff dissolution at $12 \quad 240^{\circ}$ C. J. Hydrol., 209: 81-111.

13 Kemper, W.D. 1960. Water and ion movement in thin films as influenced by the electrostatic 14 charge and diffuse layer of cations associated with clay mineral surfaces. Soil Sci. Soc. Am. $15 \quad$ Proc., 24:10-16.

16 Kozaki, T., K. Inada, S. Sato, and H. Ohashi. 2001. Diffusion mechanism of chloride ions in 17 sodium montmorillonite. J. Contam. Hydrol., 47: 159-170.

18 Lide, D.R. (Editor-in-Chief). 2000. CRC Handbook of Chemistry and Physics, 81st Edition. Boca 19 Raton, Florida, CRC Press.

20 Nakashima, S. 1995. Diffusivity of ions in pore water as a quantitative basis for rock deformation 21 rate estimates. Tectonophysics, 245(3-4): 185-203. 
UCRL-JRNL-201012

1 Neck, V., and B. Kanellakopulos. 1987. Partial molar volume and effective ionic radius of the

$2 \quad \mathrm{TcO}_{4}{ }^{-}$ion in aqueous solution. Radiochim. Acta, 42:135-137.

3 Polak, A., R. Nativ and R. Wallach. 2002. Matrix diffusion in northern Negev fractured chalk and 4 its correlation to porosity. Water Resourc. Res., 268:203-213.

5 Roberts, J.R., and W. Lin. 1997. Electrical properties of partially saturated Topopah Spring tuff: $6 \quad$ Water distribution as a function of saturation. Water Resour. Res., 33(4): 577-587.

7 Rundberg, R.S. 1987. Assessment report on the kinetics of radionuclide adsorption on Yucca 8 Mountain tuff. Los Alamos National Laboratory. LA-11026-MS, New Mexico.

9 Russo, R.E., X.L. Mao, O.V. Borisov, and H.C. Liu. 2000. Laser ablation in atomic spectroscopy. 10 Encyclopedia of Analytical Chemistry: Instrumentation and Applications. John Wiley \& 11 Sons.

12 Shackelford, C. 1991. Laboratory diffusion testing for waste disposal - A review. J. Contam. $13 \quad$ Hydro., 7:177-217.

14 Stewart, G.L. 1972. Clay water interactions, the behavior of ${ }^{3} \mathrm{H}$ and ${ }^{2} \mathrm{H}$ in adsorbed water and the 15 isotope effect. Soil Sci. Soc. Amer. Proc., 36:421-426.

16 Tokunaga, T. K., and J. Wan. 1997. Water film flow along fracture surfaces of porous rock. Water $17 \quad$ Resour. Res., 33: 1287-1295.

18 Tokunaga, T.K., J. Wan, and S.R. Sutton. 2000. Transient film flow on rough fracture surfaces. 19 Water Resour. Res., 36(7): 1737-1746.

20 Tokunaga, T.K., K.R. Olson, and J. Wan. 2003. Moisture characteristics of Hanford gravels: Bulk, 21 grain-surface, and intragranular components. Vadose Zone J., 2: 322-329. 
1 Tomutsa, L., D. Doughty, A. Brinkmeyer, and S. Mahmood. 1992. Imaging techniques applied to 2 the study of fluids in porous media. NIPER-582. National Institute for Petroleum and Energy 3 Research, Bartlesville, OK.

4 Triay, I.R., A. Meijer, J.L. Conca, K.S. Kung, R.S. Rundberg, B.A. Strietelmeier, and C.D. Tait.

5 1997. Summary and synthesis report on radionuclide retardation for the Yucca Mountain

$6 \quad$ Site Characterization Project. Milestone 3784M, Los Alamos National Laboratory, Los $7 \quad$ Alamos.

8 Wang, J.S.Y., E.L. Hardin, and L.D. Rickertsen. 2001. Crushed tuff as an invert diffusion barrier 9 to enhance waste-isolation capacity. Proceedings of the $9^{\text {th }}$ International High-Level 10 Radioactive Waste Management Conference. Las Vegas, Nevada. 
UCRL-JRNL-201012

\section{Figure Captions}

Figure 1 Schematic of different components of water present in an aggregate medium and their effects on diffusion. $\mathrm{D}_{\text {Interior }}$ and $\mathrm{D}_{\text {Surface }}$ denote interior and surface diffusion, respectively. (Modified from Conca and Wright, 1992.)

\section{Figure 2 Electrical conductivity measurement cell.}

Figure 3 Half-element diffusion experimental setup and schematics of micro-scale mapping.

Face number designation is in the center of each face; face 1 and face 6 are the interface and far-side faces, respectively.

Figure 4 Cross-sectional CT images. (a) 16-25 mm tuff gravel. (b). 6.3-9.5 mm tuff gravel. Spatial resolution in the viewed plane is $\sim 0.3 \mathrm{~mm} \times 0.3 \mathrm{~mm}$. Voxel depth is $1 \mathrm{~mm}$.

Figure $51 \mathrm{~mm}$ cross-sectional CT images for $6.3-9.5 \mathrm{~mm}$ tuff gravel. (a) under a partially saturated condition. (b) water distribution (wet scan - dry scan).

Figure 6 Diffusion coefficients versus volumetric water content for this and other work.

Legend " $15 \mathrm{~mm}$ tuff, this work (LA/ICP-MS)" includes the coefficients of surface diffusion

for bromide in both cube and tetrahedron sinks (Table 2). Diffusion coefficients reported in

Conca and Wright (1992) were for 86 soil and gravel samples, various bentonites, and rock

core of tuff basalt and mudstone. The size of crushed tuff and silica sand was not reported in 9 OCRWM (2000a).

Figure 7 Tracer distributions from surface mapping using LA/ICP-MS (100 $\mu \mathrm{m}$ spot size

1 and 10 laser pulses) for cube-cube configuration after diffusion inside nearly $100 \% \mathrm{RH}$

2 chamber after 149.7 days. Y-axis: intensity ratio (dimensionless) denotes the signal of each 
tracer (solid circle: bromide; solid square: perrhenate) divided by the signal of aluminum.

2 Refer to Figure 3 for face designation.

3 Figure 8 Tracer distributions on the surface of Face 3 for both source and sink cubes inside (200 $\mu \mathrm{m}$ spot size and 20 laser pulses). (a) 98\% RH chamber after 0.79 days and (b) $44 \% \mathrm{RH}$

5 chamber after 16.3 days. X-axis: 0 indicates the interface, and increasing positive number indicates increasing distance from the interface in the sink cube.

7 Figure 9 Relative bromide concentrations in the sink elements from $98 \%$ RH experiments.

8 Lines are the fitted analytical diffusion solutions (Equation 1) with the effective diffusion $9 \quad$ coefficients shown in the legend.

10 Figure 10 Adsorption isotherm of water on (a) fully hydroxylated quartz; contact angle $=0^{\circ}$

11 (modified from Gee et al., 1990, Figure 1), and (b) heat-dehydroxylated quartz; contact angle $12=43^{\circ}($ modified from Gee et al., 1990, Figure 2). 
Table 1. Diffusion coefficients and cell conditions during EC measurements.

\begin{tabular}{|c|c|c|c|c|c|c|c|c|c|c|}
\hline $\begin{array}{c}\text { Tuff grain } \\
\text { volumetric } \\
\text { water content } \\
\left(\mathrm{cm}^{3} / \mathrm{cm}^{3}\right)^{\dagger}\end{array}$ & 0.945 & 0.194 & 0.118 & 0.118 & 0.118 & 0.114 & 0.104 & 0.103 & 0.097 & 0.098 \\
\hline $\begin{array}{c}\text { Cell } \\
\text { volumetric } \\
\text { water content }\end{array}$ & 0.547 & 0.092 & 0.055 & 0.055 & 0.055 & 0.052 & 0.050 & 0.052 & 0.049 & 0.05 \\
\hline $\begin{array}{l}\text { Intergranular } \\
\text { porosity }\end{array}$ & 0.494 & 0.494 & 0.494 & 0.494 & 0.494 & 0.539 & 0.517 & 0.495 & 0.494 & 0.487 \\
\hline $\operatorname{Avg} D_{e}\left(\mathrm{~m}^{2} / \mathrm{s}\right)$ & $6.53 \mathrm{E}-10$ & $3.46 \mathrm{E}-11$ & $1.39 \mathrm{E}-11$ & $1.48 \mathrm{E}-11$ & $1.36 \mathrm{E}-11$ & $5.27 \mathrm{E}-12$ & $2.22 \mathrm{E}-12$ & $2.03 \mathrm{E}-12$ & $2.00 \mathrm{E}-12$ & $1.24 \mathrm{E}-12$ \\
\hline
\end{tabular}

$\dagger \quad$ Calculated volumetric water content based on the crushed tuff bulk volume (=volume of water/total volume of tuff grains including intragranular porosity). Values exceeding the grain porosity (0.105) indicate conditions beyond grain saturation.

$\$ \quad$ Calculated volumetric water content based on the cell volume (=volume of water/cell volume) 
Table 2. Experimental conditions and measured diffusion coefficients

\begin{tabular}{|c|c|c|c|c|c|c|c|}
\hline $\begin{array}{l}\text { Half-element } \\
\text { configuration }\end{array}$ & $\begin{array}{c}\text { Relative } \\
\text { humidity } \\
(\%)\end{array}$ & $\begin{array}{c}\text { Bulk } \\
\text { liquid } \\
\text { saturatio } \\
\mathrm{n}(\%)\end{array}$ & $\begin{array}{l}\text { Exp. } \\
\text { time } \\
\text { (d) }\end{array}$ & $\begin{array}{l}\text { Sampling } \\
\text { locations }\end{array}$ & Tracer & $\begin{array}{l}\text { Effective } \\
\text { diffusion } \\
\text { coefficient } \\
\left(\mathrm{m}^{2} / \mathrm{s}\right)\end{array}$ & $\mathrm{D}_{B r} / \mathrm{D}_{\text {Perrherate }}$ \\
\hline \multirow{4}{*}{ Cube-Cube } & \multirow{4}{*}{98} & \multirow{4}{*}{88.76} & \multirow{4}{*}{0.79} & \multirow{2}{*}{ Surface } & Bromide & $8.0 \mathrm{E}-11$ & \multirow{2}{*}{1.60} \\
\hline & & & & & Perrherate & $5.0 \mathrm{E}-11$ & \\
\hline & & & & \multirow{2}{*}{ Interior } & Bromide & $6.0 \mathrm{E}-11$ & \multirow{2}{*}{1.50} \\
\hline & & & & & Perrherate & $4.0 \mathrm{E}-11$ & \\
\hline \multirow{2}{*}{$\begin{array}{l}\text { Cube- } \\
\text { Tetrahedron }\end{array}$} & \multirow{2}{*}{98} & \multirow{2}{*}{71.65} & \multirow{2}{*}{1.14} & \multirow{2}{*}{ Surface } & Bromide & $4.0 \mathrm{E}-11$ & \multirow{2}{*}{1.14} \\
\hline & & & & & Perrherate & $3.5 \mathrm{E}-11$ & \\
\hline \multirow{4}{*}{ Cube-Cube } & \multirow{4}{*}{93} & \multirow{4}{*}{50.15} & \multirow{4}{*}{16.17} & \multirow{2}{*}{ Surface } & Bromide & 4.0E-11 & \multirow{2}{*}{2.00} \\
\hline & & & & & Perrherate & $2.0 \mathrm{E}-11$ & \\
\hline & & & & \multirow{2}{*}{ Interior } & Bromide & $4.0 \mathrm{E}-11$ & \multirow{2}{*}{3.33} \\
\hline & & & & & Perrherate & $1.2 \mathrm{E}-11$ & \\
\hline \multirow{4}{*}{ Cube-Cube } & \multirow{4}{*}{76} & \multirow{4}{*}{22.93} & \multirow{4}{*}{16.24} & \multirow{2}{*}{ Surface } & Bromide & $1.5 \mathrm{E}-12$ & \multirow{2}{*}{1.88} \\
\hline & & & & & Perrherate & 8.0E-13 & \\
\hline & & & & \multirow{2}{*}{ Interior } & Bromide & $1.0 \mathrm{E}-12$ & \multirow{2}{*}{2.50} \\
\hline & & & & & Perrherate & $4.0 \mathrm{E}-13$ & \\
\hline \multirow{2}{*}{$\begin{array}{c}\text { Cube- } \\
\text { Tetrahedron }\end{array}$} & \multirow{2}{*}{76} & \multirow{2}{*}{24.47} & \multirow{2}{*}{27.24} & Surface & Bromide & $5.0 \mathrm{E}-13$ & 125 \\
\hline & & & & surace & Perrherate & $4.0 \mathrm{E}-13$ & $1.2 \mathrm{~J}$ \\
\hline & & & & Surfoce & Bromide & $1.5 \mathrm{E}-14$ & 125 \\
\hline $\mathrm{Cl}_{\mathrm{S}} \mathrm{C}$ & & & & Surrace & Perrherate & $1.2 \mathrm{E}-14$ & 1.25 \\
\hline taod caod & J & 1.5 & 10.20 & tarion & Bromide & $1.8 \mathrm{E}-14$ & 150 \\
\hline & & & & 110 & Perrherate & $1.2 \mathrm{E}-14$ & 1.50 \\
\hline Cube- & 43 & 420 & 2732 & Surface & Bromide & $4.0 \mathrm{E}-14$ & 201 \\
\hline Tetrahedron & To & 1.20 & & & Perrherate & $2.0 \mathrm{E}-14$ & \\
\hline
\end{tabular}

$\dagger \quad$ The value is the bulk liquid saturation for the sink element, and the measured porosity is $0.0827 \pm 0.0036$ for eight tuff cubes. 
Figure 1

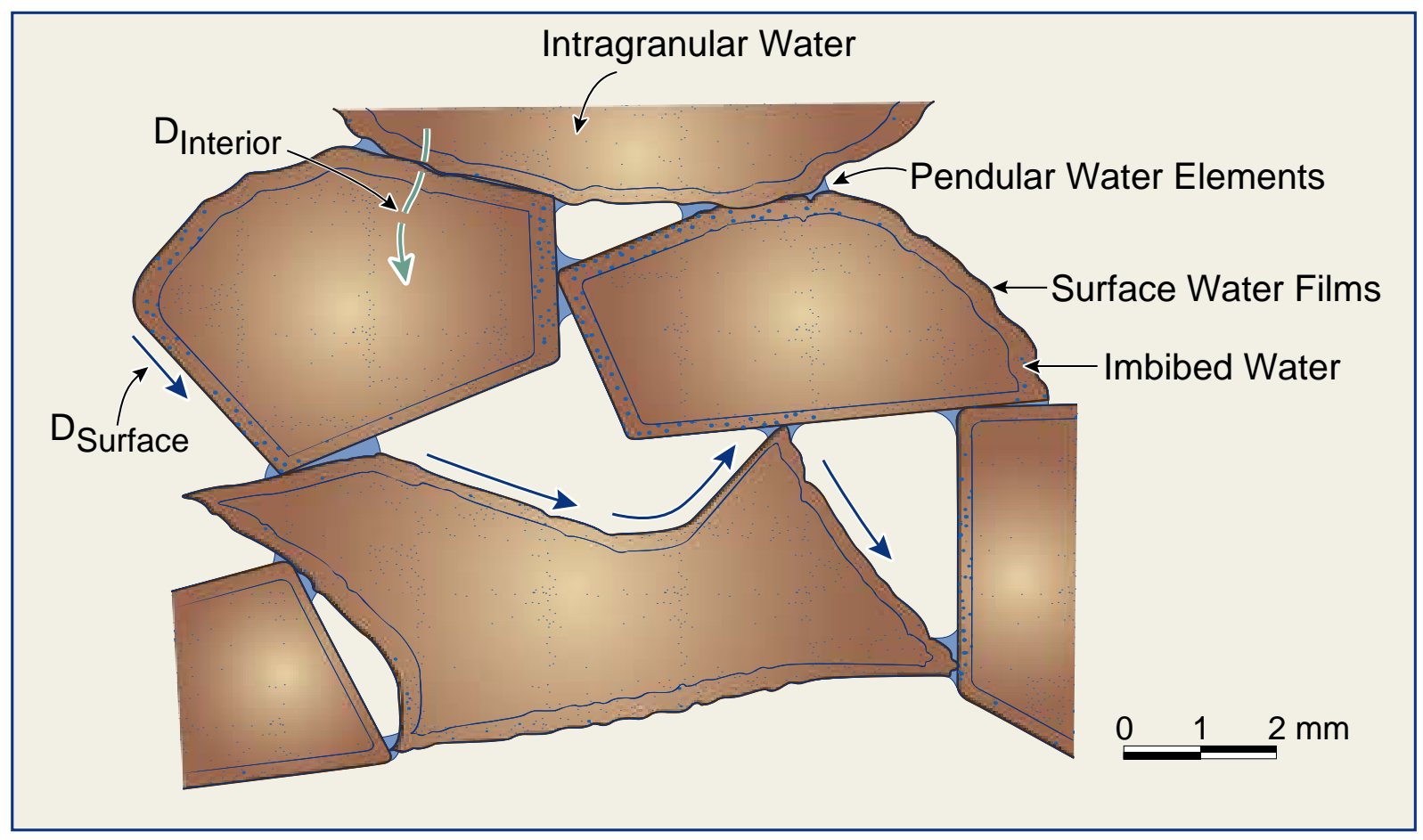


Figure 2

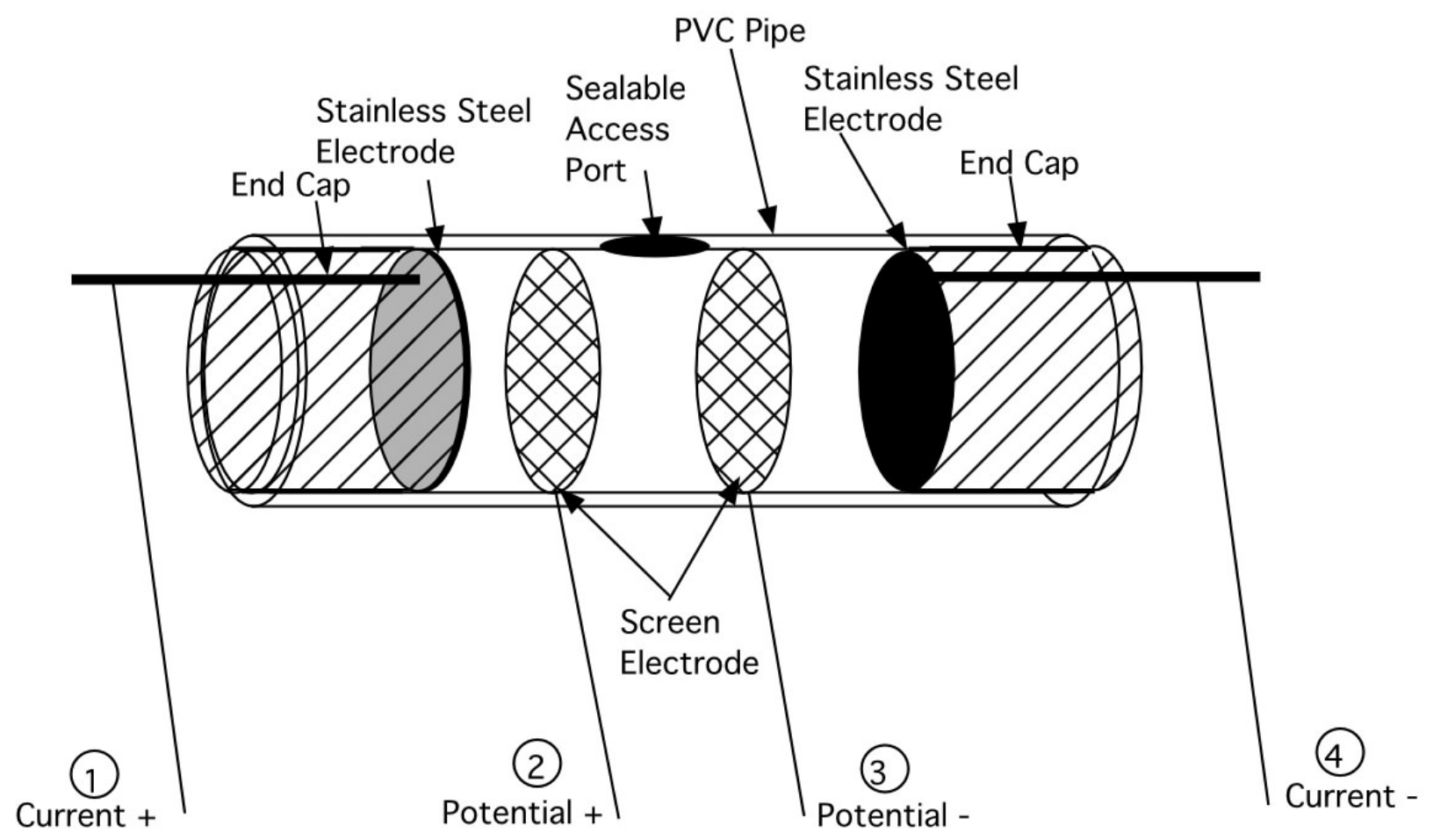


Figure 3

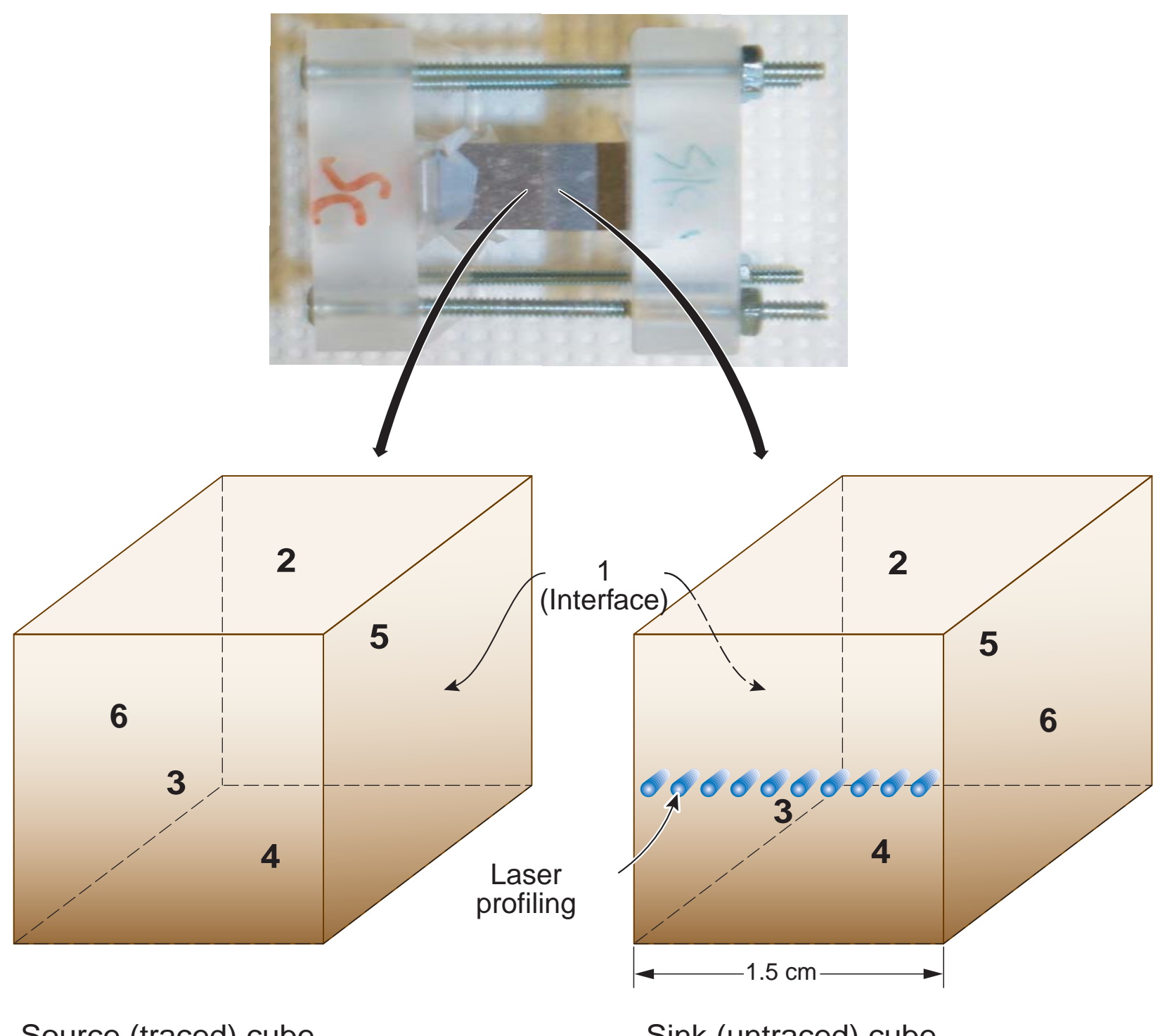

Source (traced) cube

Sink (untraced) cube 
Figure 4

(a)

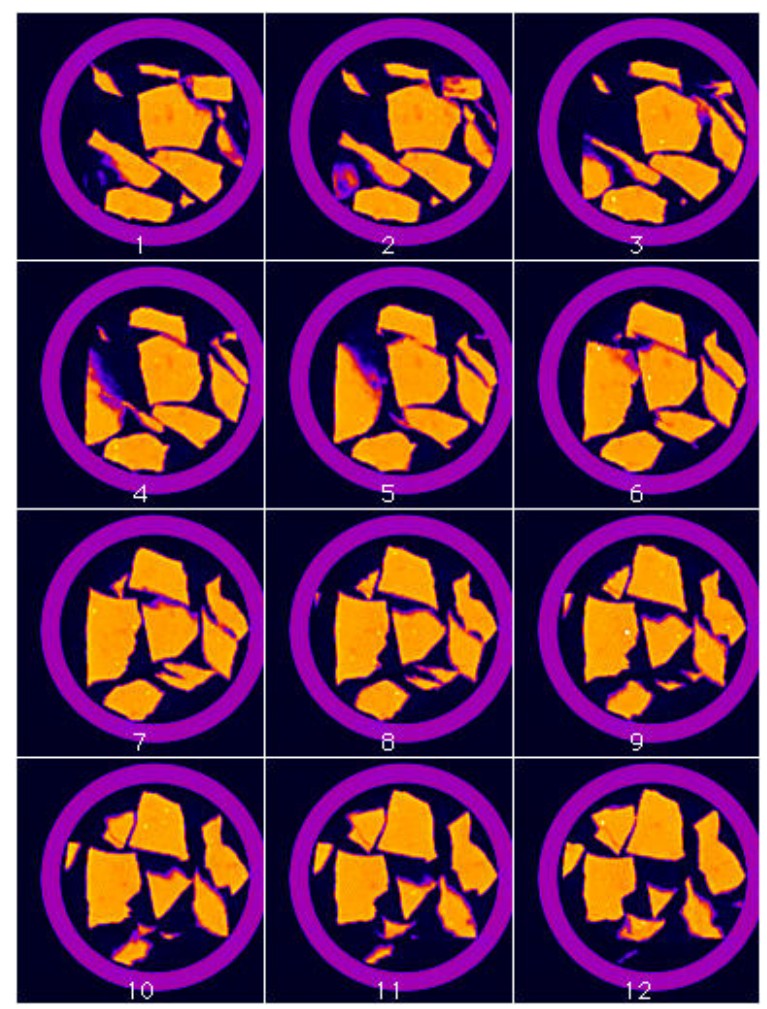

(b)

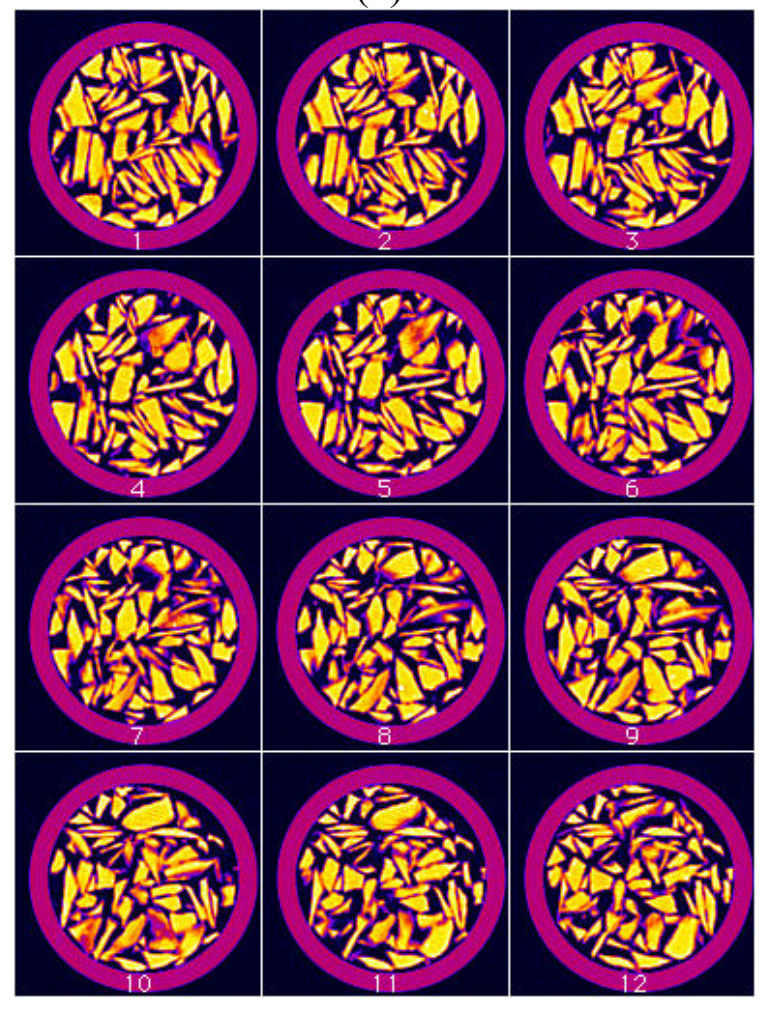


Figure 5

(a)

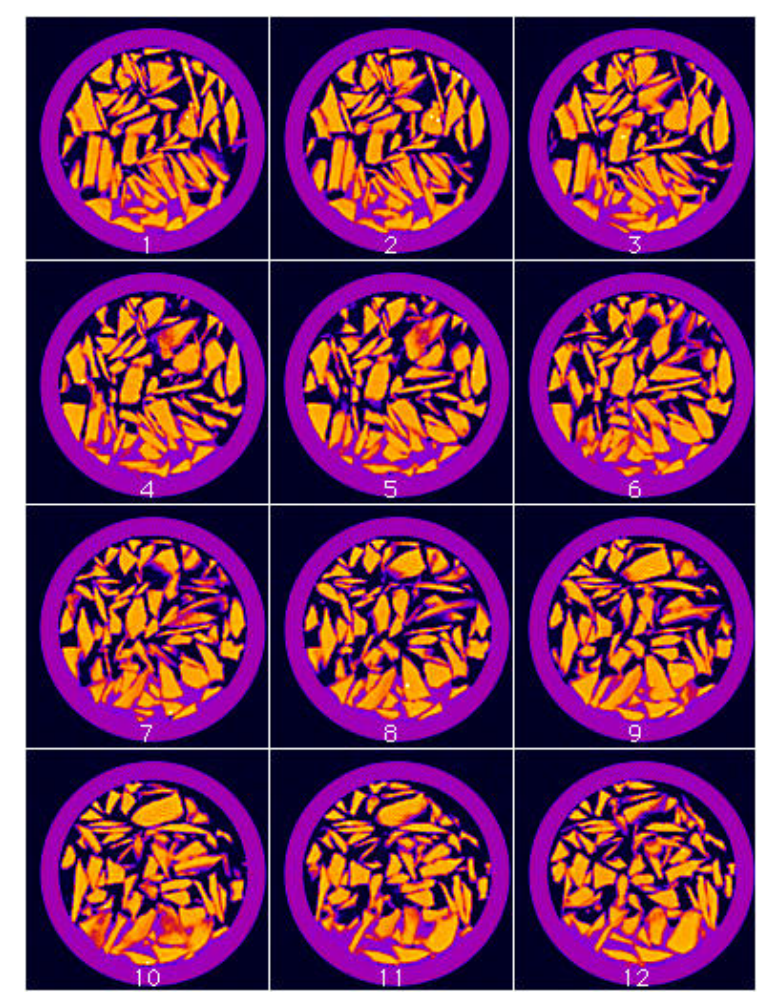

(b)

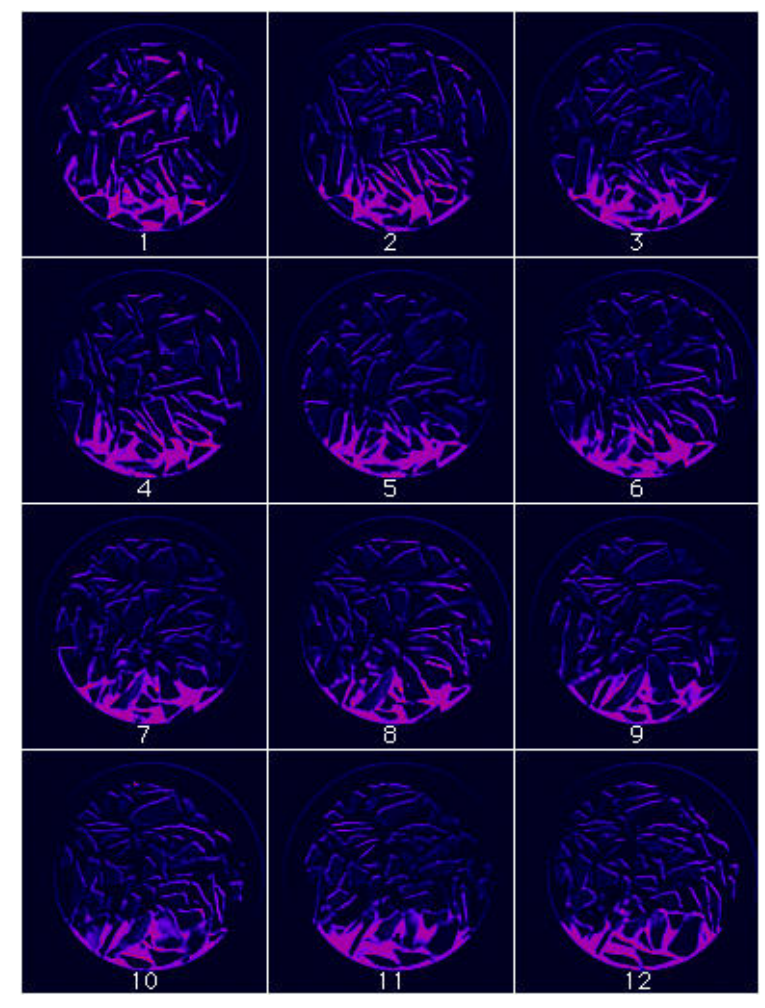




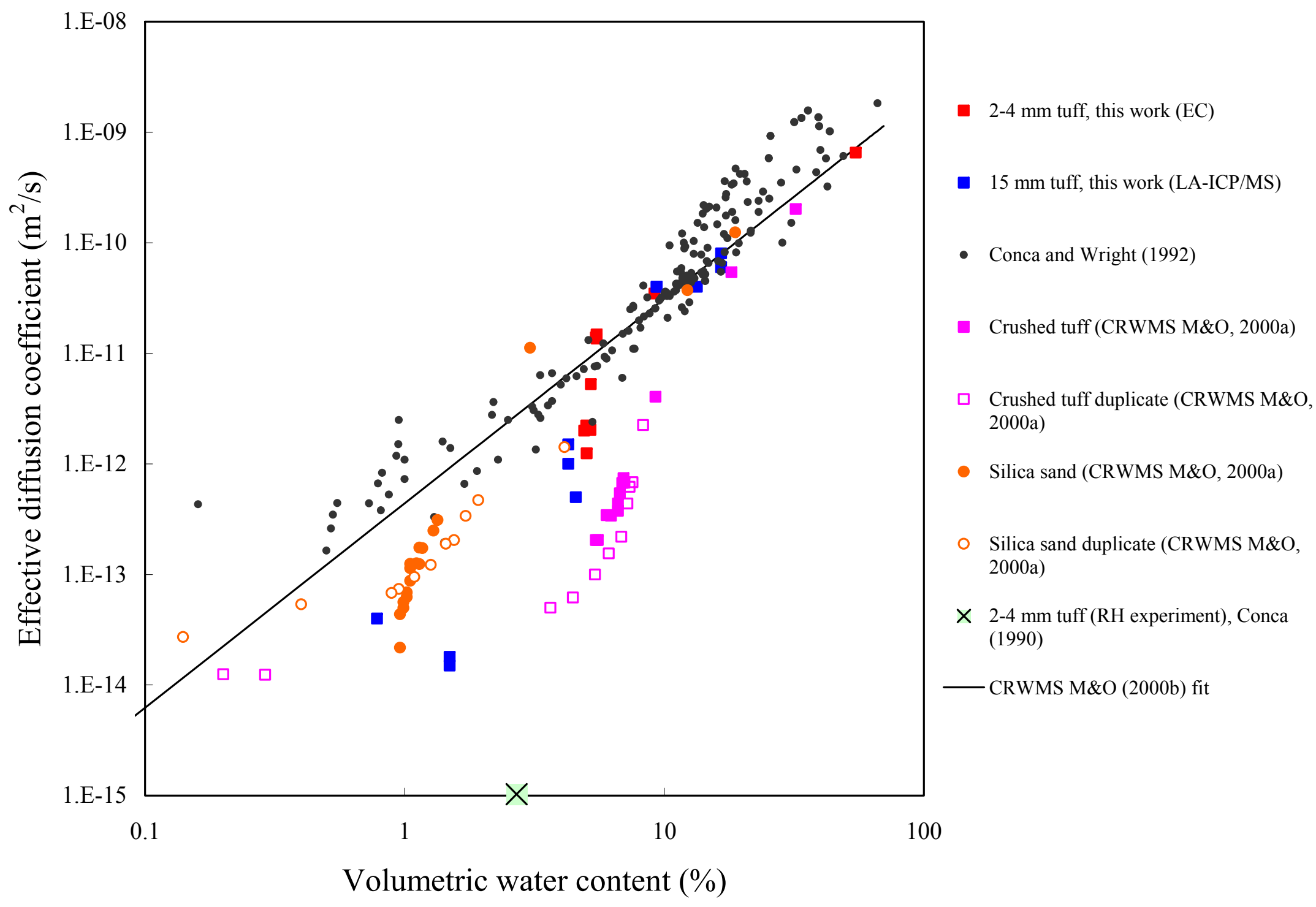

Figure 6 


\section{Figure 7}

Source (traced) Cube
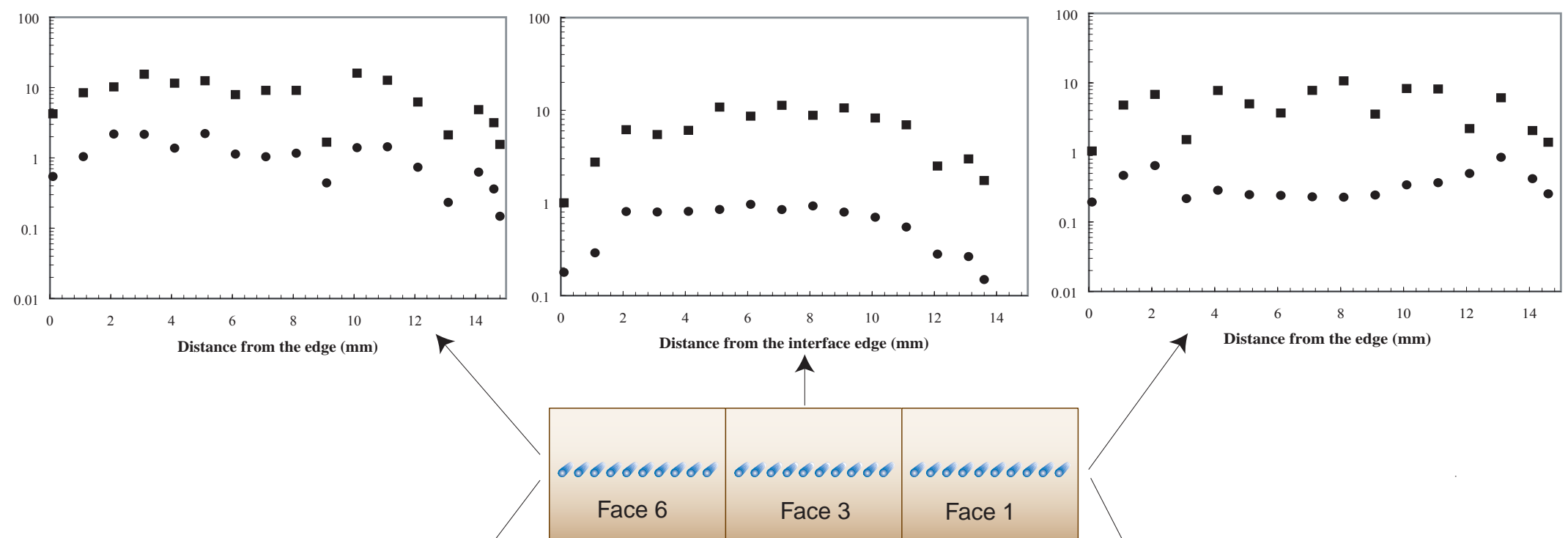

Sink (untraced) Cube
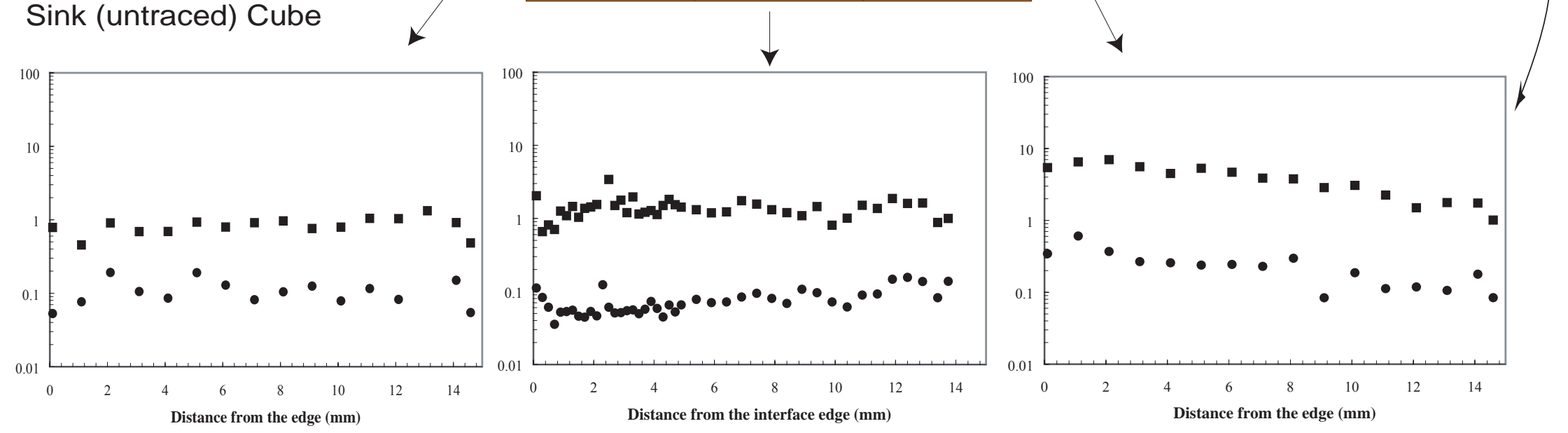


\section{Figure 8}
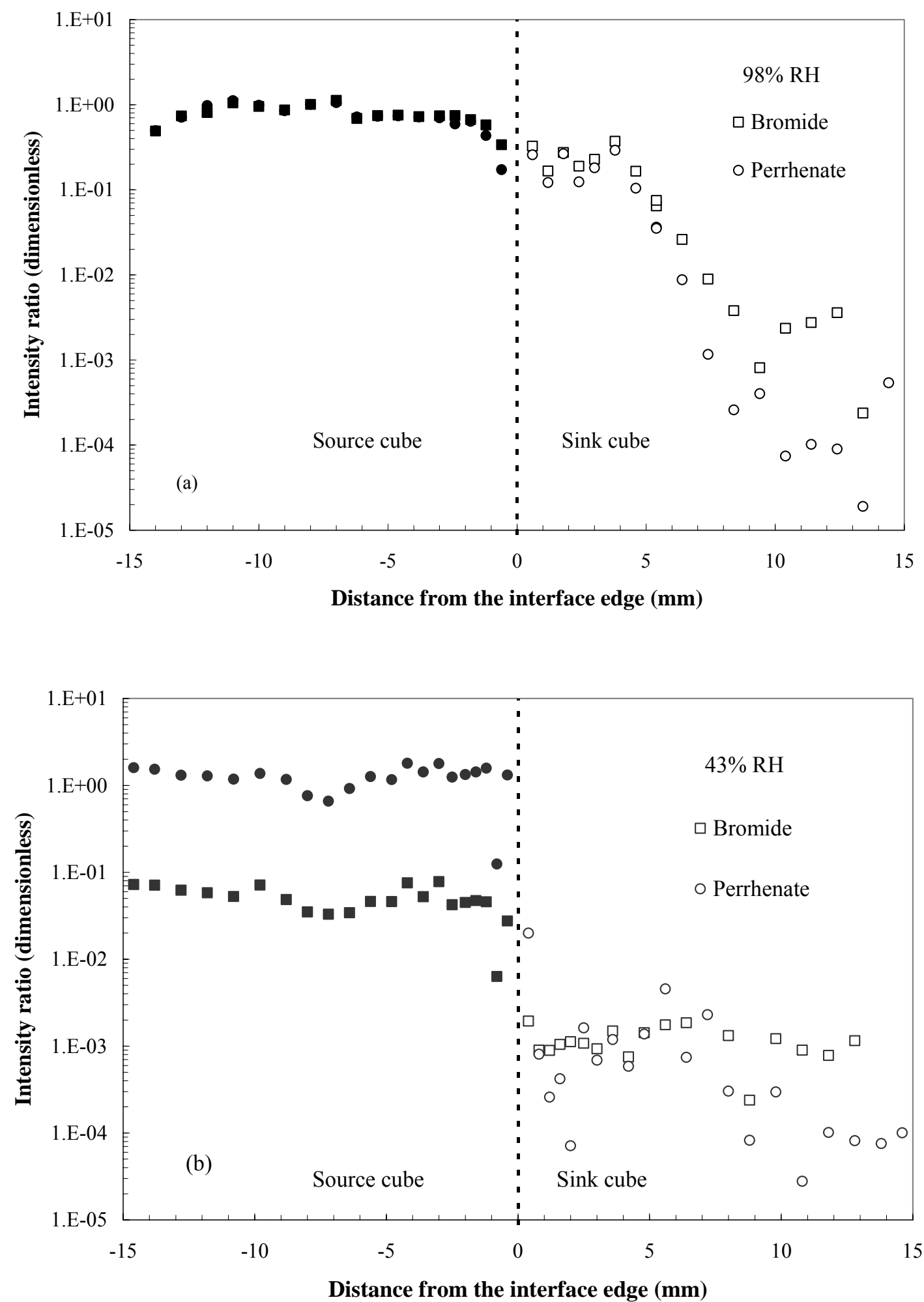
Figure 9
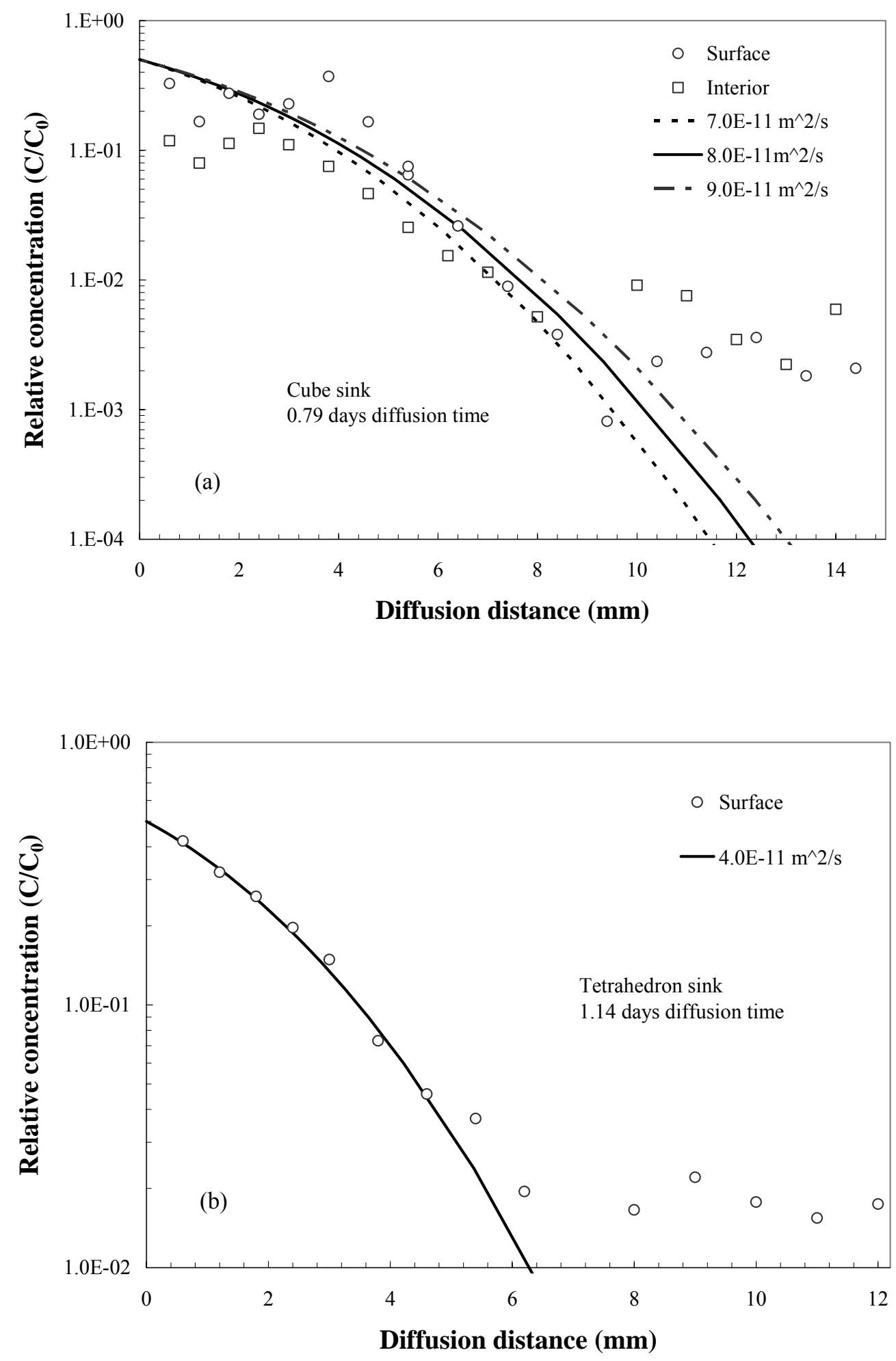
Figure 10
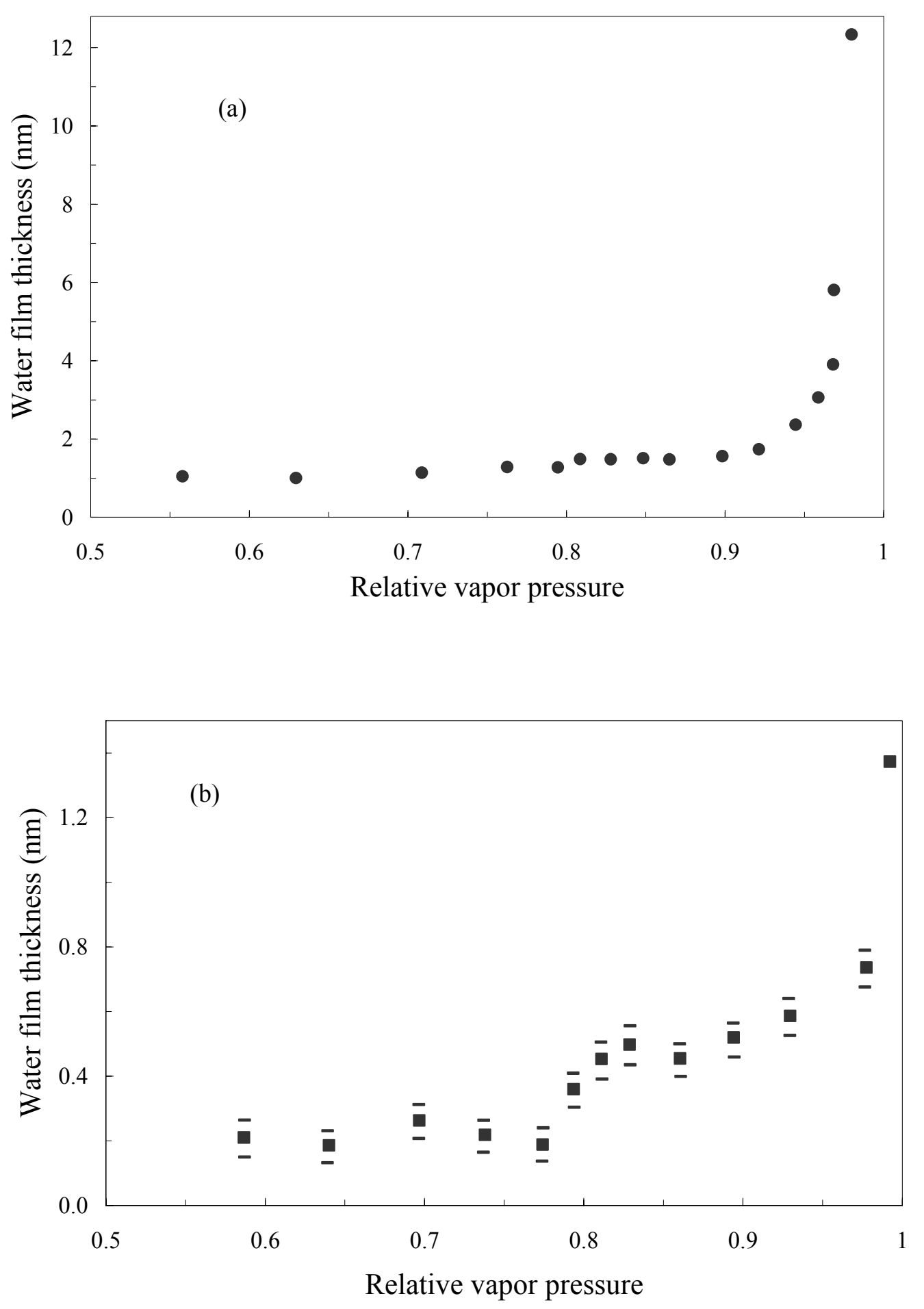